\title{
A GIS Pre and Post Processing Contribution to a Multi Techniques Test Survey for an Ancient Railway Restoration in the Brembana Valley
}

\author{
Barbara Marana \\ Department of Engineering and Applied Science, University of Bergamo, Dalmine (Bergamo), Italy \\ Email: barbara.marana@unibg.it
}

How to cite this paper: Marana, B. (2018) A GIS Pre and Post Processing Contribution to a Multi Techniques Test Survey for an Ancient Railway Restoration in the Brembana Valley. Journal of Geographic Information System, 10, 573-602. https://doi.org/10.4236/jgis.2018.105031

Received: August 28, 2018

Accepted: October 26, 2018

Published: October 29, 2018

Copyright $\odot 2018$ by author and Scientific Research Publishing Inc. This work is licensed under the Creative Commons Attribution-NonCommercial International License (CC BY-NC 4.0).

http://creativecommons.org/licenses/by-nc/4.0/

\begin{abstract}
Stemming from the renewed desire to requalify the former Brembana Valley railway route (inside one of the valleys of the Province of Bergamo and close to the important city of Milan), from Bergamo to Villa d'Almè, in 2017, the Bergamo Transport Company and other partners have signed a memorandum of understanding. They have also entrusted a project company to develop a technical and economic viability study, which would be an update of a preliminary one presented in 2009. A private proposal for the realization of a test survey, useful for the required engineering project, has been submitted to the project company and accepted. For this reason, a team, comprising different companies, and among them also the Geomatics group at the University of Bergamo, was formed so as to perform this task and develop it in a degree thesis. The aim of the test survey is to evaluate a joint use of the new available technologies, so as to possibly get faster, more economic and thorough results, by performing a $3 \mathrm{D}$ metric analysis over two sub-areas selected along the route. The paper describes this experience and the achieved results. In particular, the areas of interest in the test project have been analyzed first thing with a GIS software and then surveyed with a multi-sensor approach, i.e. terrestrial laser scanner, GNSS techniques and UAV. The final integrated results allowed providing a metric model of the morphological and urban aspect for the territorial layout, useful also for further advanced GIS analyses. The analysis of the reached precisions has provided satisfactory results which agree with the metric requirements of the project. Further meaningful considerations can be derived from this test survey: the implementation of different techniques has helped to overcome problems due to hidden parts in complex objects, it has allowed to provide a faster survey and to test different technologies and software packages. The results have been quite satisfactory.
\end{abstract}




\section{Keywords}

Brembana Valley, Railway, Restoration, Test Survey, Multi Sensor Acquisition, Integrated Results, GIS Analyses

\section{Introduction}

In July 2017, a joint venture [1], involving A.T.B. Spa (Bergamo Transport Company) [2] and the partner territorial agencies, assigned to T.E.B. (Electric Tramway of Bergamo) [3] which involved E.T.S. (Engineering and Technical Services) group [4], the task to provide an economical and technical viability study so to restore and requalify the abandoned old route of the Brembana Valley Railway, from the town of Bergamo to Villa d'Almè. The project would be an update of a preliminary one presented in 2009. This renewed interest has stemmed from the conviction that the development of the infrastructure is going to provide an economic and social welfare to the population living in the Valley and in the Bergamo hinterland. Engineer Riccardo Begnis from Scan2BIM [5], a company partner of the architectural design company $\mathrm{R}+\mathrm{TB}$ [6], devoted to laser scanner surveys and Building Information Modeling, then contacted E.T.S. [4]. The proposal has been to test, over some areas selected along the railway route planned in the preliminary project, the joint use of the modern survey technologies, so as to evaluate the possibility to provide faster, more economic and thorough results. With T.E.B. [3] and E.T.S. [4] approval and their selection of the test areas, the survey project has been pursued by the architectural design company $\mathrm{R}+\mathrm{TB}$ [6] with the collaboration of different teams [5] [7] [8], together with the now retired Professor Colombo of the Geomatics group, School of Engineering at the University of Bergamo. Then, also two students, at the University of Bergamo-Engineering, were involved with the aim to study the argument in their degree thesis.

For this reason, a test project has been studied by the teams involved [5] [6] [7] [8] and the Geomatics group. The aim is to recreate the territorial and urbanistic 3D model of some areas of interest, selected along the railway route, with the aid of the most up-to-date technologies.

This choice is meant to provide useful geo-referenced metric information for the project of a new light tramway which will be called Tramway 2 or T.E.B. [3] T2 line.

The hope is that this new line could be finally carried out; for this reason, as above said, an agreement protocol has been signed [9].

The renewed interest to restore the whole route of the former Val Brembana railway has allowed, as explained above, to test new survey techniques and their implications, over two test sub-areas chosen by T.E.B. [3] along the route in the preliminary project.

The two selected areas are placed in two commons quite close to the city of 
Bergamo, they closely represent the morphological layout of the territory in which the railway route laid out and can be reached easily in a short time. It is expected that the results will provide: a more complete $3 \mathrm{D}$ model of the two sub-areas, useful information about the pros and cons of a joint-techniques survey and considerations about the different software packages to be employed for the point clouds processing and further analyses.

The two testing areas, to be measured in a 3-Dimensional way, are quite wide and of heterogeneous nature, i.e. with buildings, green areas, road infrastructures and other artefacts, such as the former Paladina railway station and the bridge over the Rino river. The natural and fastest choice, to achieve the desired mapping scale (which has been selected at 1:200 for the two artefacts and 1:500, 1:1000 for the territorial areas) and a suitable metric resolution, would have been an image-based photogrammetric approach, with the employment of UAVs (Unmanned Aerial Vehicles), so as to transport the shooting instruments.

This way, the land obstacles, related to the geometry of the objects, the accessibility of the site and the speed of the survey acquisition, would have been solved. Anyway, the existing artefacts, mentioned above, are quite complex 3D objects, difficult to be managed only with the photogrammetric technique; for this reason, a synergic employment, with the addition of a laser scanner, has allowed to get the necessary spatial data for a global metric restitution at the desired scale. In fact, it is nowadays possible to choose different surveying instruments, applying both active and passive sensors in a synergic way. A survey with a terrestrial laser scanner, working as active sensor with light radiation, allows to get dense 3D point clouds which provide the geometrical and spatial information useful to achieve a 3 Dimensional model, by registering data from the bottom up [10]-[16].

However, to provide a more complete $3 \mathrm{D}$ model, it could be useful to add a UAV aerial approach (usually an image-based survey) to the terrestrial laser acquisition. In fact, this traditional aerial technique has been recently revalued thanks to the meaningful software and hardware improvements [17]-[23].

It is important to underline that UAVs allow to carry digital photo cameras or photogrammetric calibrated cameras and even the most recent light laser scanners. UAVs are completely automated and auto-piloted thanks to the addition of GNSS (Global Navigation Satellite System) devices for the trajectory management while flying. They show a high versatility and for this reason they represent a useful integration to achieve the desired results. Obviously each technique offers its pros and cons [24] [25] and so a joint use of both could be considered the best choice [26]-[32].

\section{The Brembana Valley Railway: The History}

The idea of establishing a railway in the Brembana Valley [33] in the Province of Bergamo [34] (Figure 1) is quite ancient, stemming back to 1885 [35]. In that year, the Province technical offices were appointed to study a project of a railway 
from the town of Bergamo to San Pellegrino. San Pellegrino Terme is a common (Figure 2) of 4826 inhabitants, an area of $22.95 \mathrm{~km}^{2}$ and at an altitude of $358 \mathrm{~m}$ over the sea level [36]. Located in the Province of Bergamo and the Brembana Valley, San Pellegrino was famous for its waters, which are also well known nowadays in all the world [37]. In 1902 a big thermal structure, together with a Casino (Figure 3), a Grand Hotel (Figure 4) and also a funicular service were inaugurated. All these buildings well reflected the Liberty style, the Italian term for Art Nouveau, of the epoch [38]. The main characters of this style are: friezes, frescos, mosaics, curved lines and the employment of new materials such as iron, glass, porcelain, clay and concrete [39]. The great amount of visitors and tourists, mostly from Milan, was a boost for the economy of the common, and indirectly of the Valley, which was certainly going to thrive. The widespread reputation of San Pellegrino acted as a leverage in the project of the Brembana Valley railway and, in fact, two stops were contemplated in its territory.

A thorough research of publications describing the history of the Brembana Valley railway has been accomplished, so as to achieve a better knowledge of the steps which allowed to build this infrastructure [42] [43] [44] [45] [46].

The project, with the aim of providing the valley with an electric railway, was approved on the $15^{\text {th }}$ of March 1903 and, on the $7^{\text {th }}$ of February 1904, an assembly was convened in which a new society, named Anonymous Society of the Electric Railway of the Brembana Valley, shortly indicated as FVB, was founded.

Also another railway was projected and constructed in the near Seriana Valley and it was active from 1884 to 1967; however, the two lines have always been separated and with different company names. Figure 5 shows the route of the Brembana Valley railway in red on the left, together with the route of the Val Seriana Railway, also in red on the right, twisting in the adjacent Seriana Valley.

In July 1906 the new railway line, with a length of $25.92 \mathrm{~km}$, from Bergamo to San Pellegrino Terme was opened; later, in October a short new tract was added up to the common of San Giovanni Bianco. At the beginning there were steam trains and they lasted for only one year, when electric trains replaced them and allowed to achieve a travel time of 54 minutes for a distance of $30.333 \mathrm{~km}$, from Bergamo to San Giovanni Bianco.

The people, living in the high part of the Brembana Valley fervently asked for the railway extension, but this project was realized only after the first World War, when other $10.500 \mathrm{~km}$ were added to the original line and the final stop was established in the common of Piazza Brembana. All the stations and stops of the route of the Brembana Valley Railway were positioned between the one in Bergamo (Bergamo FVB) and the other one in the High Brembana Valley (Piazza Brembana).

The implementation of this incredible project requested, in time, the building of tunnels, viaducts, bridges, electric lines, new poles and also a new locomotive and new wagons (Figure 6); new materials, quite innovative for the epoch, were employed, such as steel and reinforced concrete [48]. 


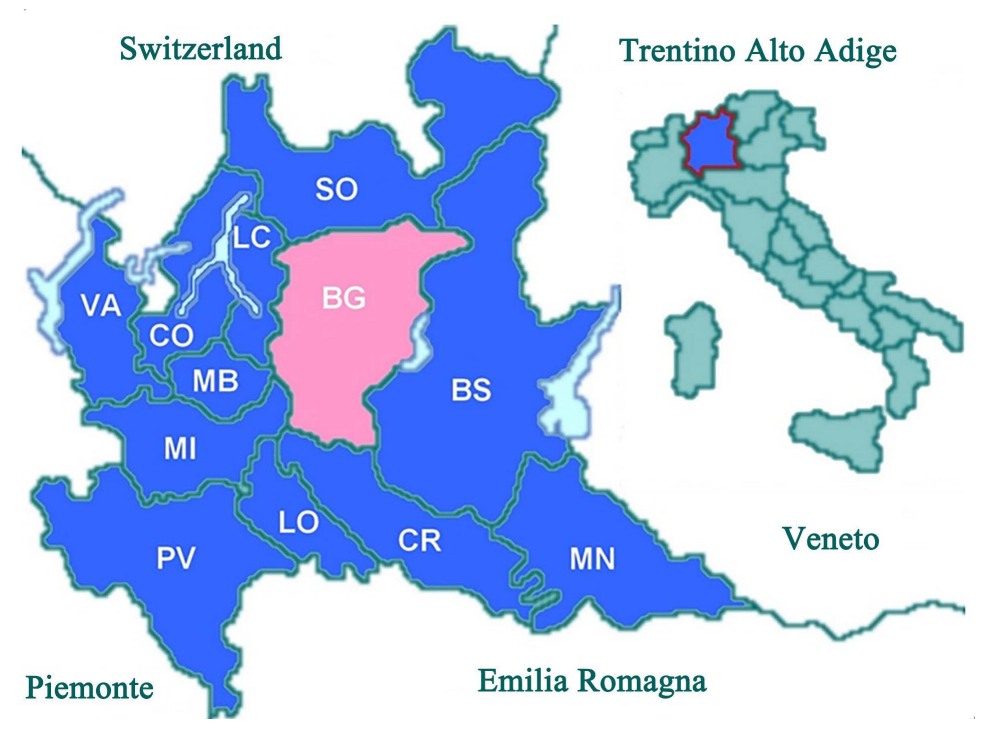

Figure 1. The Province of Bergamo in northern Italy [40].

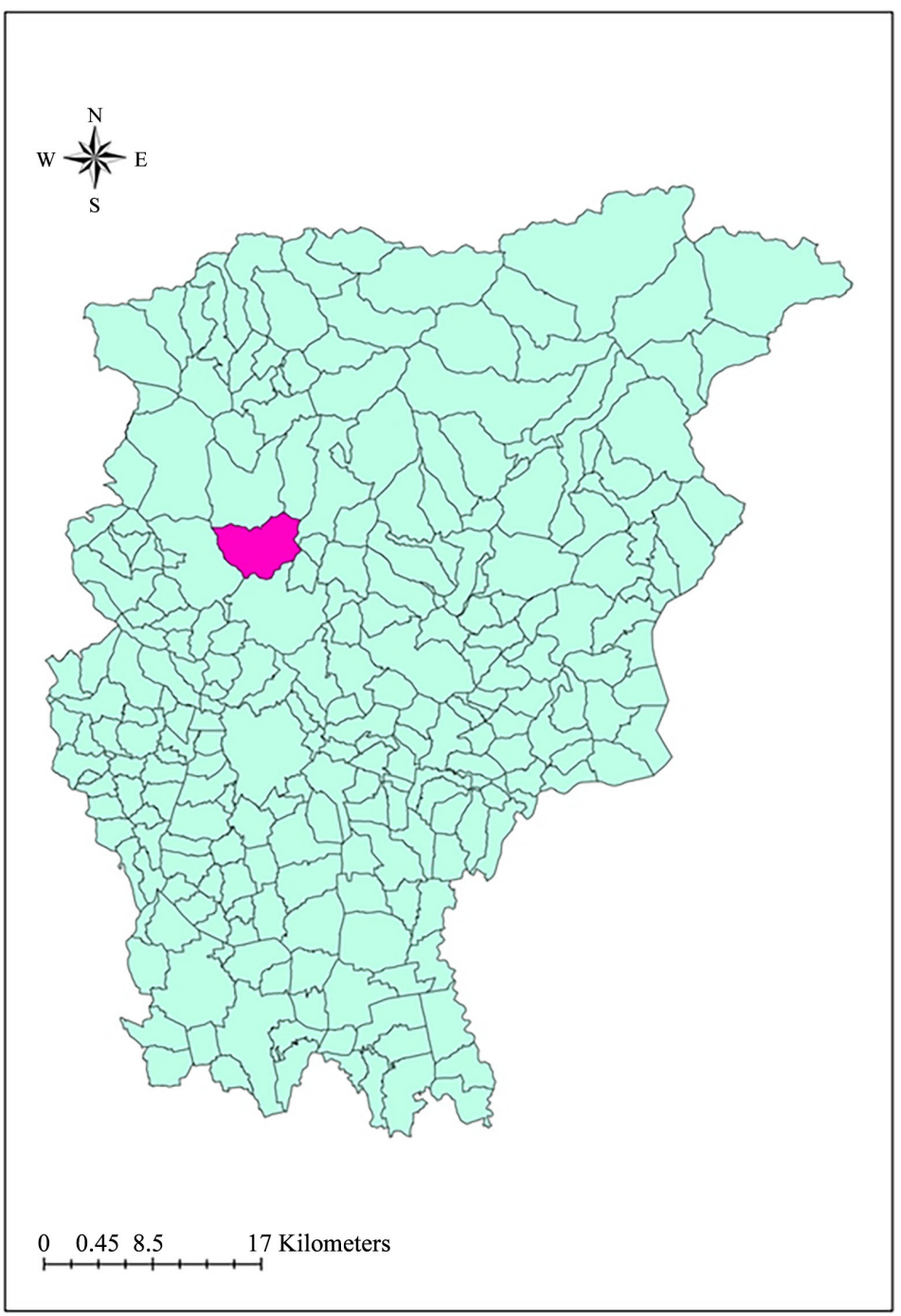

Figure 2. The common of San Pellegrino Terme in The Province of Bergamo. 


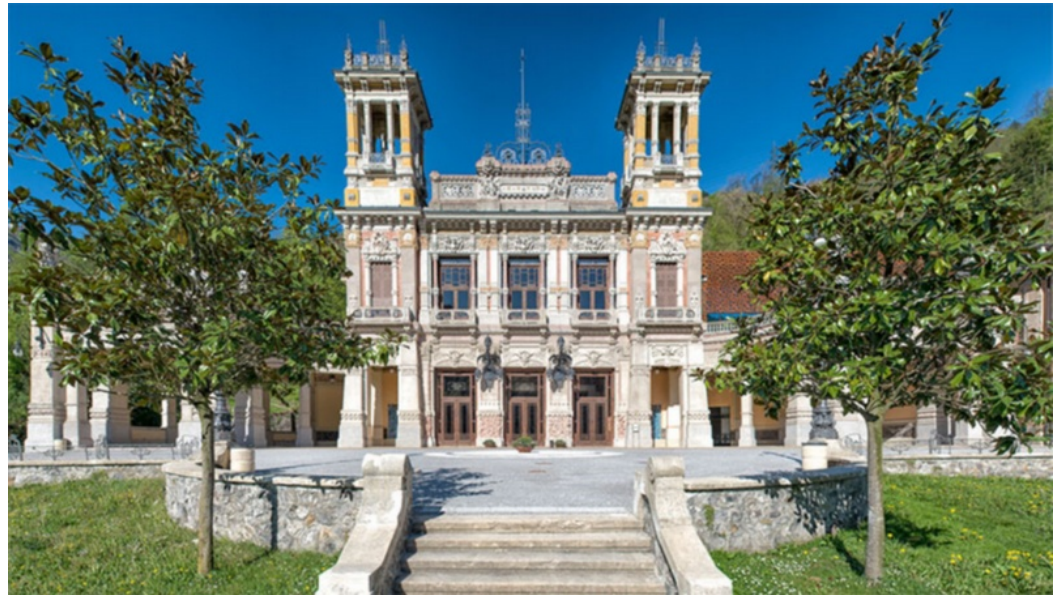

Figure 3. The Municipal Casino of San Pellegrino Terme [41].

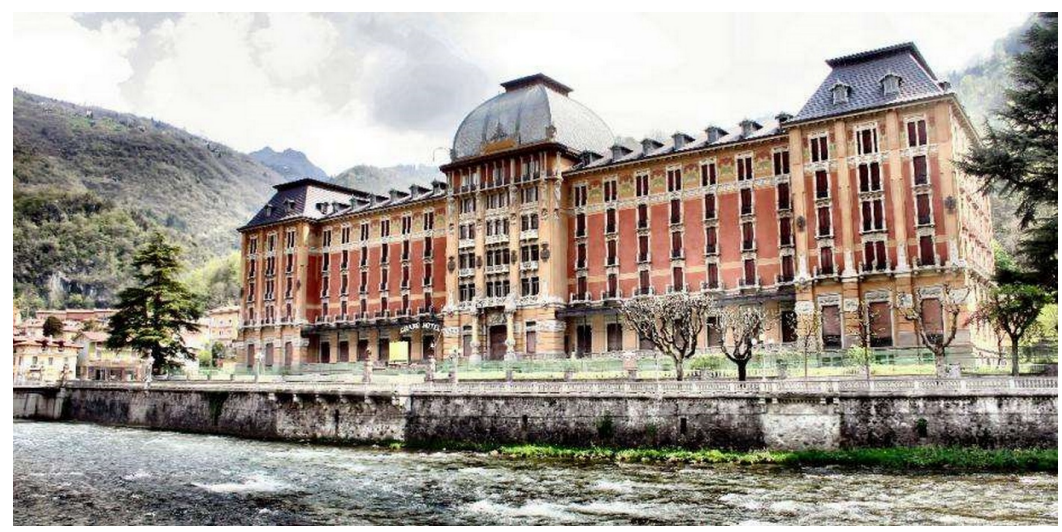

Figure 4. The Grand Hotel of San Pellegrino Terme [41].

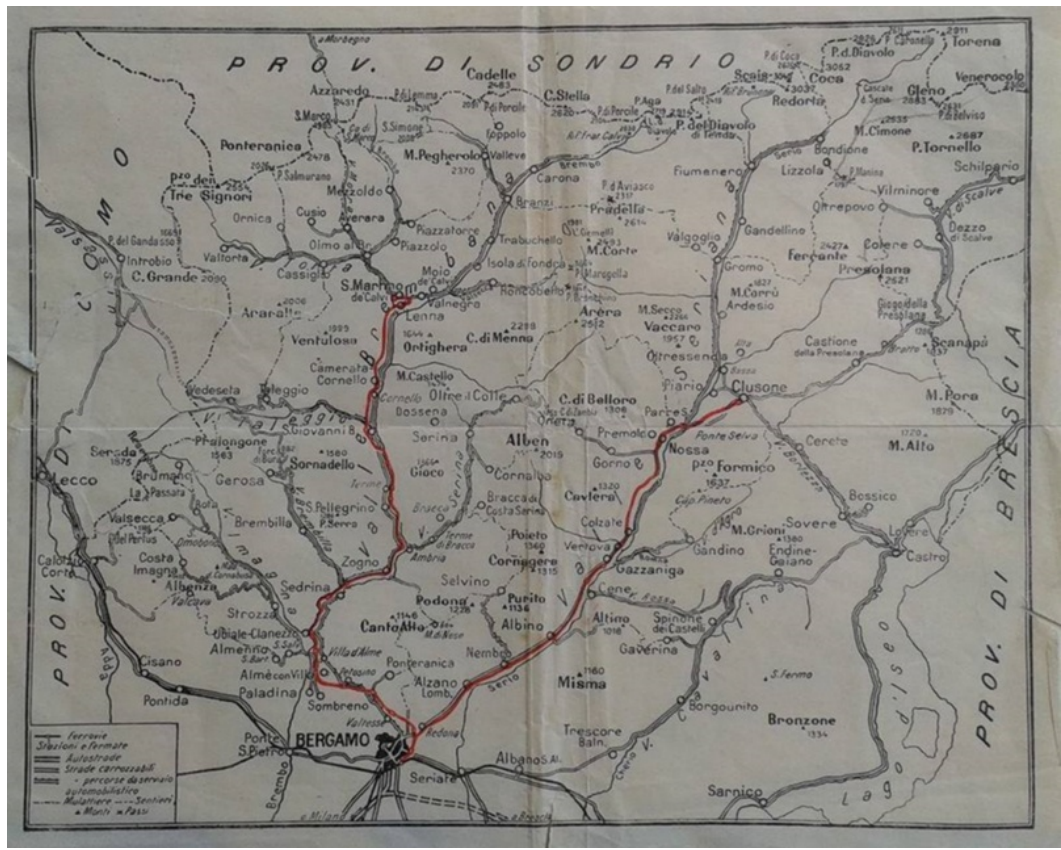

Figure 5. The Brembana Valley railway route (the red route on the left) and the Val Seriana Railway (the red route one the right) [47]. 


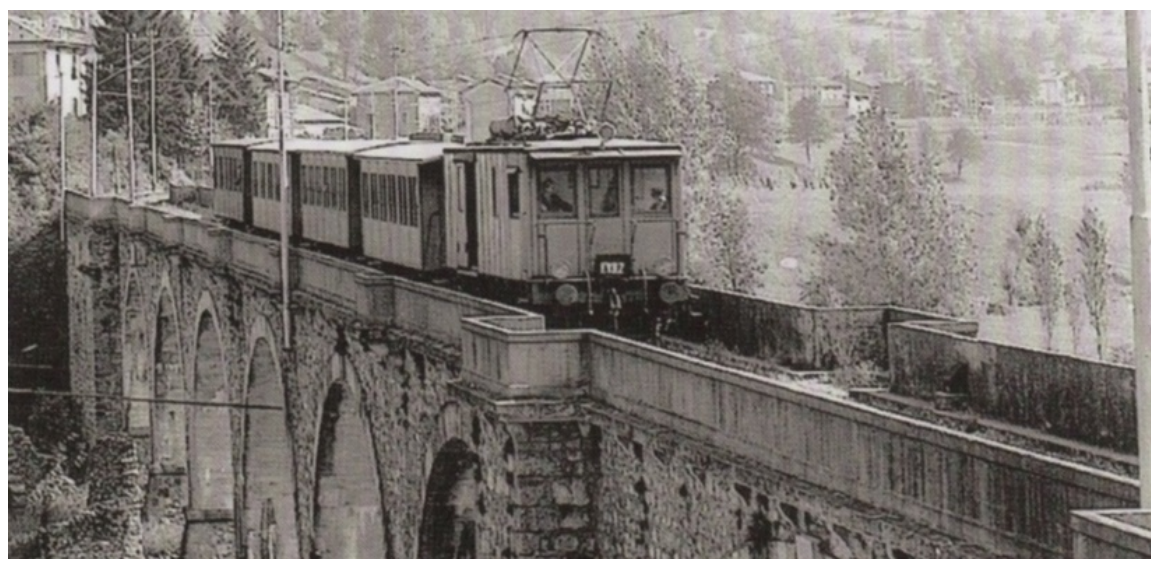

Figure 6. The locomotive and wagons over the Lenna viaduct bridge [49].

Many difficulties had to be faced and solved for its implementation, many of them related to the mountainous landscape in which the railway was set. The Brembana Valley railway had also the aim to fulfil the requests due to the rising of the new processing plants for the exploitation of the abundant metal veins. In fact, these factories allowed to employ local workers which before were obliged to emigrate in search for a job to get a subsistence for them and their families. It has also to be mentioned that the new railway would have helped to develop the existing wood, material, cheese and meat factories, as well the climatic and bathing resorts. In fact, the High Brembana Valley is characterized by many quarries of marble and building stones, the high availability of wood, a beautiful natural landscape, the mild climate in spring and the healthy properties of the waters always summoning more and more tourists. Also the electric plants fervently developed thanks to this new transport service. The new line was also a mean to divert the traffic from the too much crowded provincial street.

Anyway everything started to change when a new public bus transport service started to work in the Valley and became a serious and dangerous competitor; in fact, in time, the railway timetable was highly reduced and it served only the local workers. Finally, in 1966, the Brembana Valley railway was closed [50]. The causes were many and, among them, the high level of decay of the line iron structures, due to the money not invested in its maintenance.

\section{The Restoration Preliminary Project}

The aim of this work is to acquire the basic metric information useful for the realization of a project for the rehabilitation of the former Brembana Valley railway, from Bergamo to Villa d'Almè; in fact, the T.E.B. (Bergamo Electric Tramway) company [3], together with A.T.B. (Bergamo Transport Company) [2], wants to transform it into a light tramway. For this reason, after contacting the project society E.T.S. [4] and with their and T.E.B. approval, some teams [5] [6] [7] [8] and the Geomatics group at the University of Bergamo-Engineering] were involved in a test project over two selected test sub-areas along the route. Consequently, also a degree thesis has been started at the University of Bergamo, 
School of Engineering, by two students of the geomatics area.

This way, it is important to provide a thorough description of the areas affected by the project. In fact, two small sub-areas of the global territorial layout, with the former Paladina station and the bridge over the Rino river, were selected as a testing approach described in this paper.

These two sub-areas are in two commons of the Province of Bergamo: Almè [51] (sub-area 1 with the former Paladina station) and Villa d'Almè [52] (sub-area 2 with the bridge over the Rino river). Figure 7 [4] and Figure 8 [4], provided by E.T.S. [4], show the preliminary project layout with the planned train stops, roads, railway tracks, electrical substations (SSE) and wagons storages, as explained in the legend in Figure 9. Also some areas have been devoted to urban standard, such as public space, parking lot and green area open to the public, to be established according to the settlements in the surroundings. The demarcation of the areas, to be surveyed with the UAV, is outlined in red.

For this reason, the choice has been that of a multi technique and multi resolution survey, so as to provide a scale 1:200 for the two artefacts and 1:500, $1: 1000$ for the territorial areas.

From the acquired 3D dense point clouds, it will be then possible to provide the needed documentation for the two sub-areas, as requested by E.T.S. [4] and by the project team $[5,6,7,8$ and the Geomatics group at the University of Bergamo-Engineering], listed hereafter.

For the territorial layout:

- RGB geo-referenced ortho-images;

- DEM, DTM, DSM;

- terrain contour lines at $1 \mathrm{~m}$ interval.

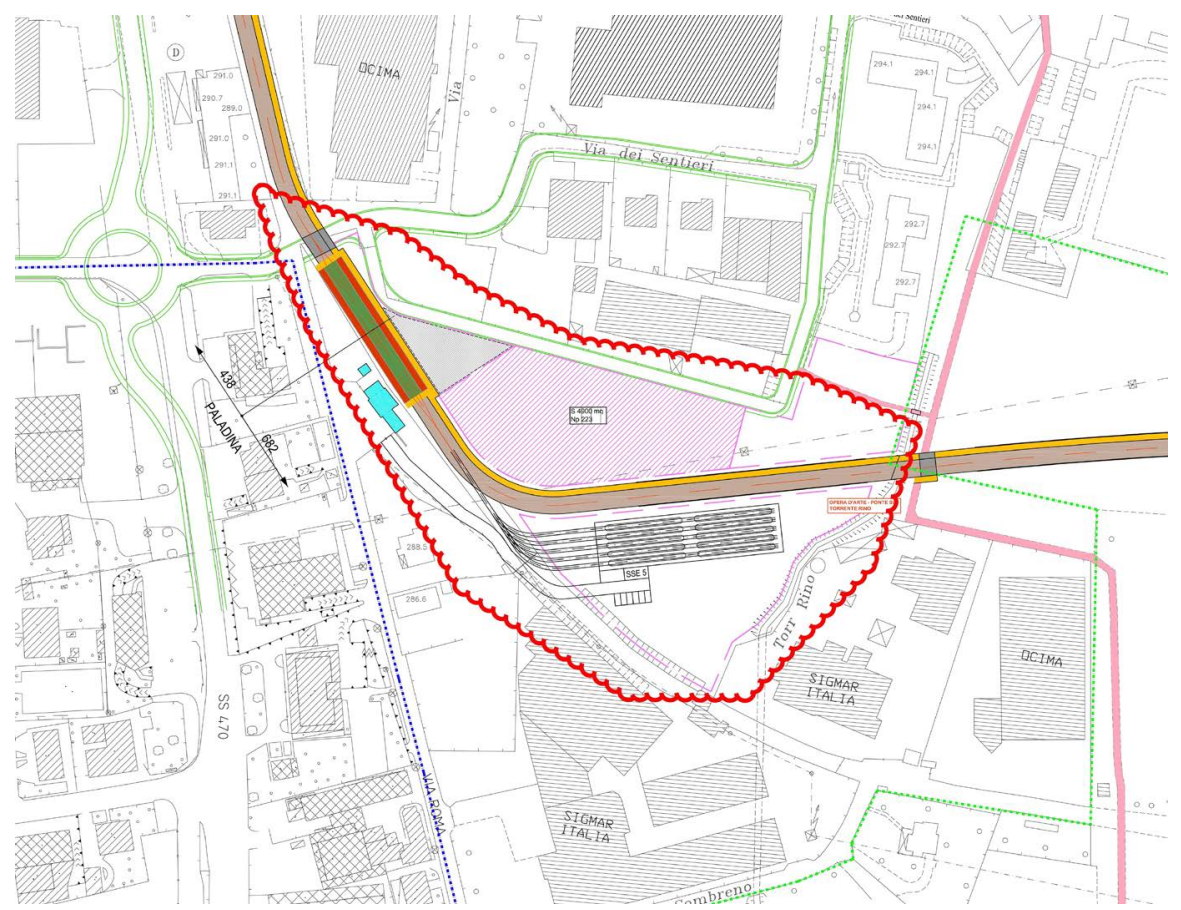

Figure 7. The project layout of the sub-area 1 in the Almè settlement [4]. 


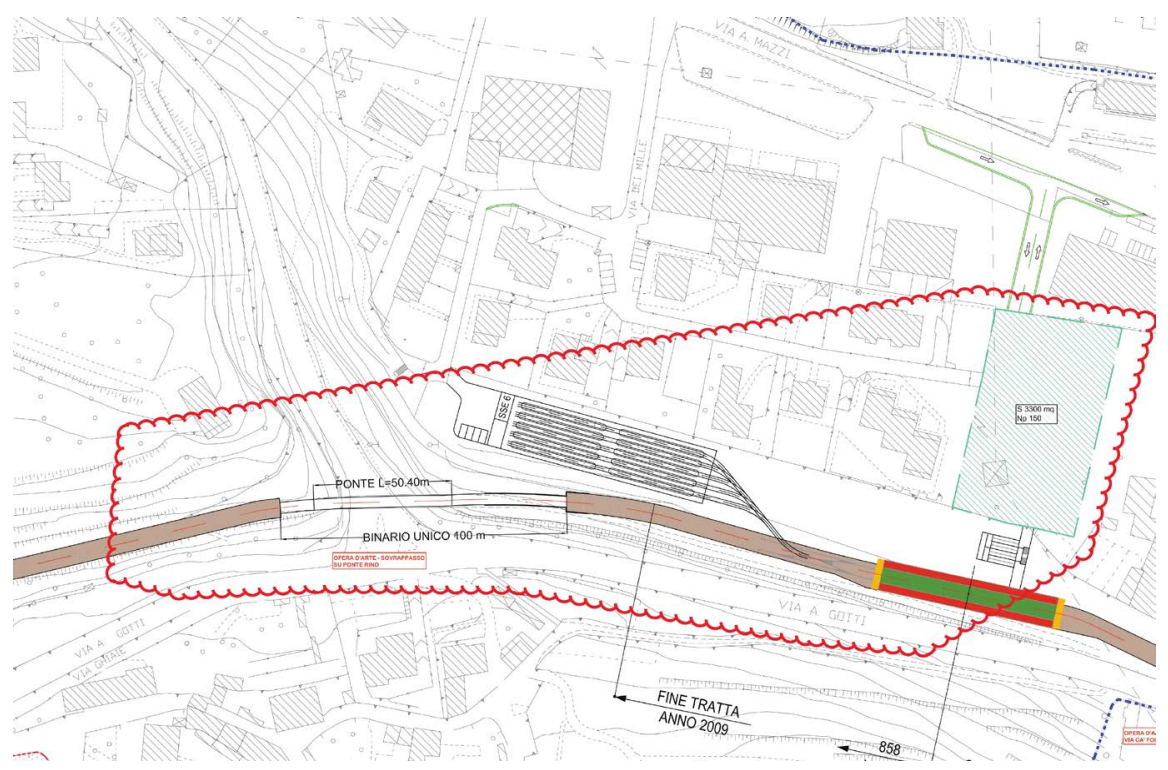

Figure 8. The project layout of the sub-area 2 in the Villa d'Almè common [4].

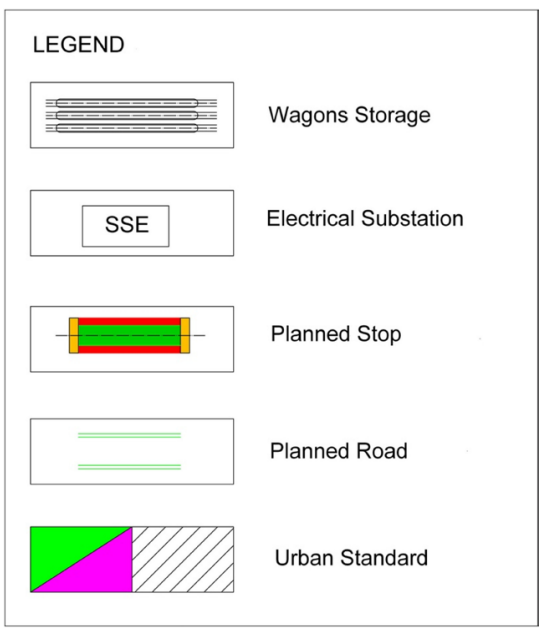

Figure 9. The legend of Figure 6 and Figure 7.

For the artefacts:

- plans, elevations and sections;

- orthographic projection of the elevations.

This documentation will be geo-referenced in the system WGS84 UTM Zone $32 \mathrm{~N}$ and it will provide the needed scale level.

\section{The Geographic and Territorial Layout}

A first territorial enquiry has been conducted with the aid of GIS techniques which allow collecting and process together many different kinds of geographic data. This means that these data need to be referenced in a common geographic reference system and only then they can be managed so as to provide the final requested information. In fact, GIS techniques allow getting a deep knowledge of the territorial layout, this way allowing making cognitive surveys, decide strate- 
gies, urban planning and interventions. In this work the Esri [53] ArcGIS software release 10.6, and its extensions, has allowed to study and analyse the territorial layout of the two selected sub-areas. The Province of Bergamo (Figure 10) extends over an area of about $2745 \mathrm{~km}^{2}$ and has a variable morphology; the northern part $(64 \%)$ is mostly mountain and here the main Valleys can be found: Brembana Valley, Seriana Valley and Cavallina Valley.

Going south, there is a band with hills (12\%) and then there is the plain area (24\%) which is part of the Padana Plain.

The two selected sub-areas are in two neighbouring commons which are in a north-west position in respect to the town of Bergamo (Figure 11):

- the smaller common of Almè, $\left(1.96 \mathrm{~km}^{2}\right)$ where the building of the former Paladina railway station is located;

- the larger common of Villa d'Almè $\left(6.36 \mathrm{~km}^{2}\right)$, where the structure of the bridge over the Rino river is located.

This way, in this initial phase of the work, GIS analyses have allowed getting a thorough knowledge with regard to the layout of the commons which contain the two (meaningful) sub-areas involved in the light tramway construction.

For this reason, some layers have been downloaded, as shapefiles, in the WGS84 UTM Zone 32N reference system, from the Lombardy Geoportal [55] and then analyzed with the package ArcGIS ArcMap release 10.6 [53]. At first, a Lombardy ortho-image [56] has allowed to see the imagery of the two commons in Esri ArcMap (Figure 12).

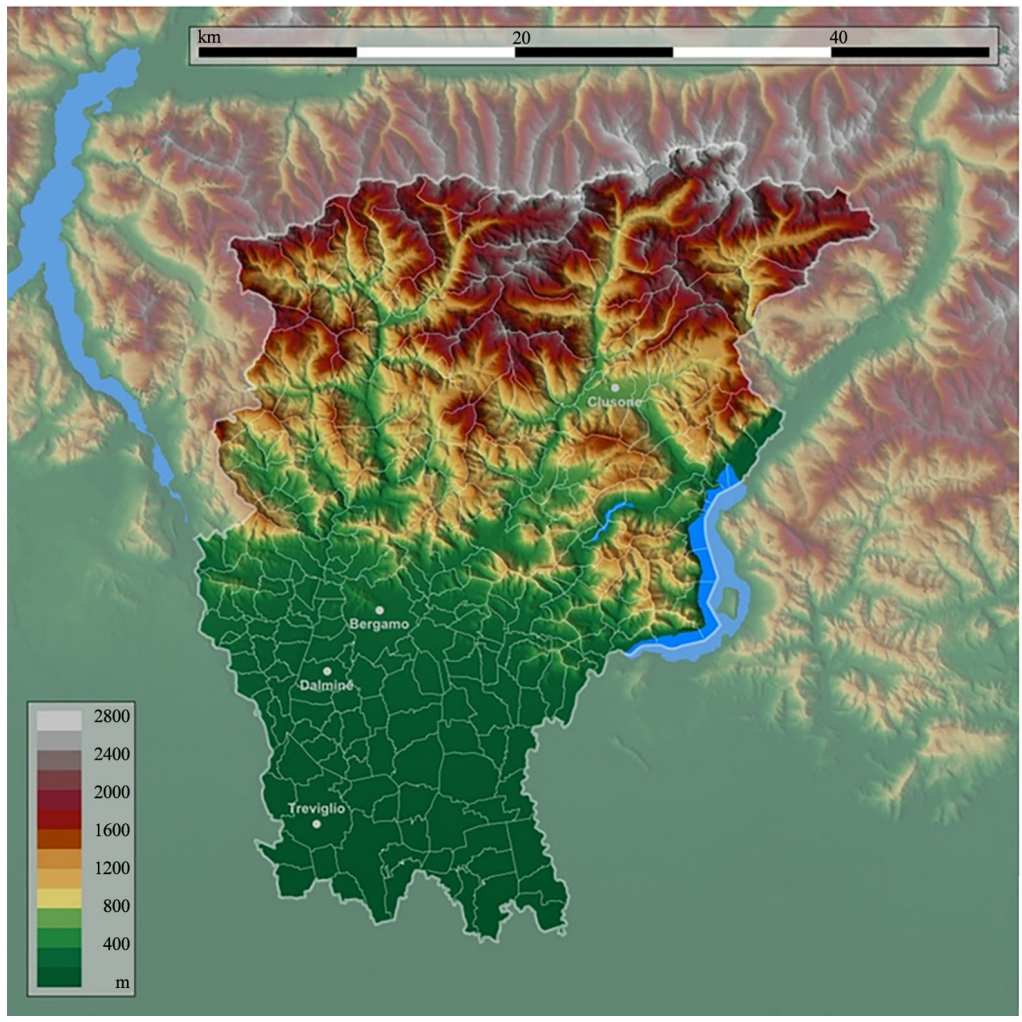

Figure 10. The Province of Bergamo territory [54]. 


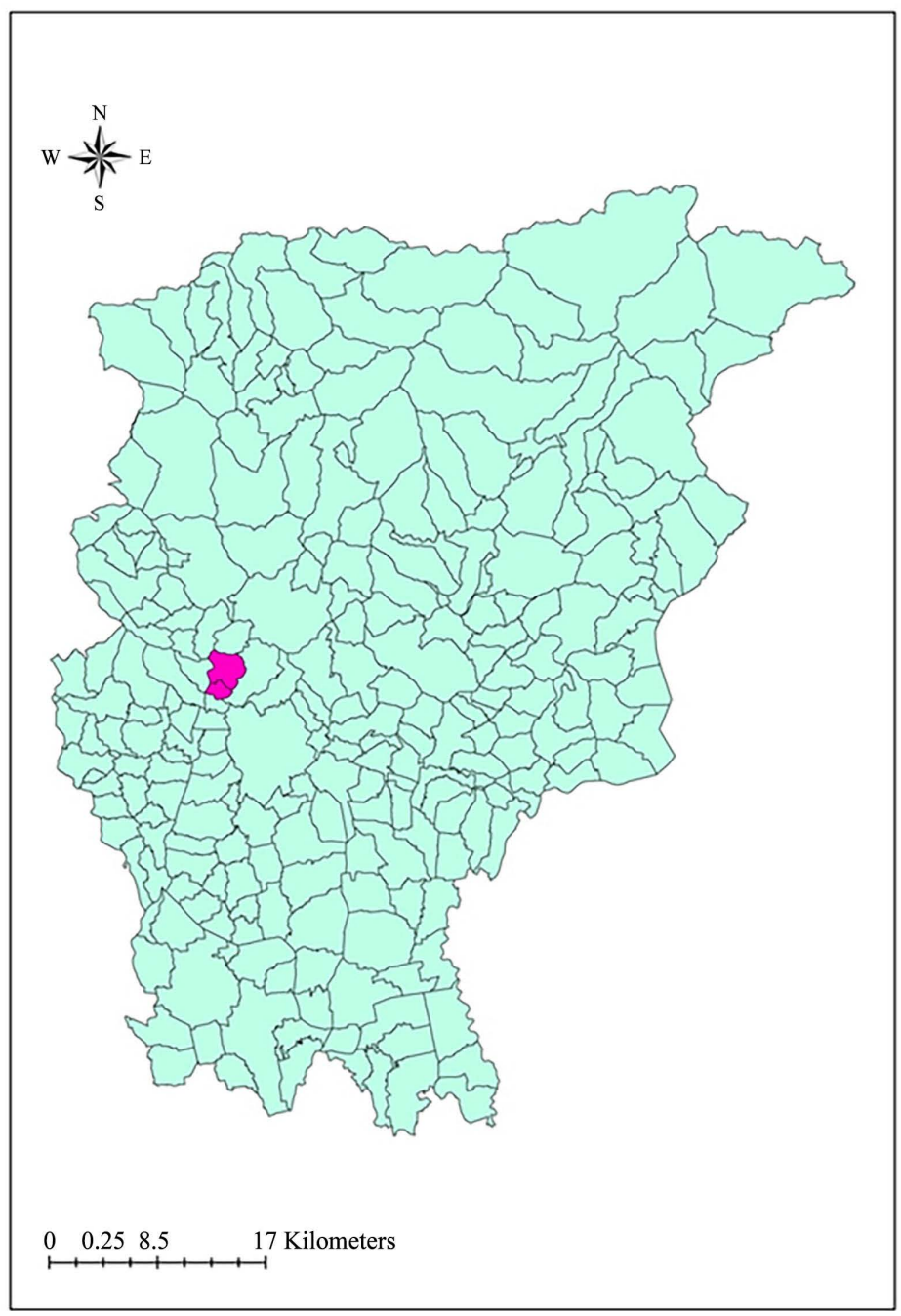

Figure 11. The neighbouring commons of Almè (under) and Villa d'Almè (above) in the Province of Bergamo.

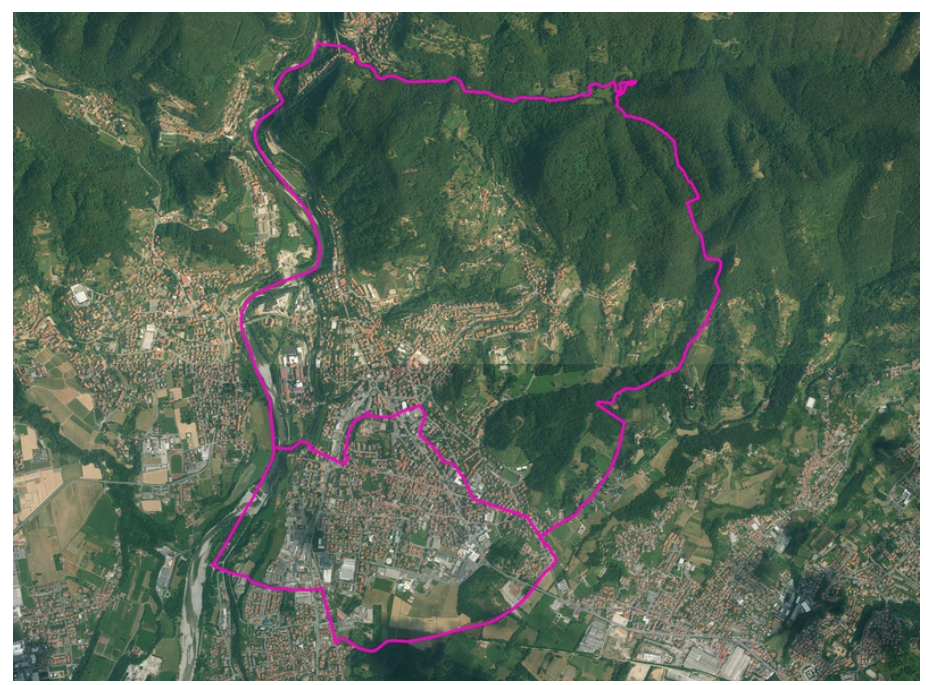

Figure 12. The Almè (under) and Villa d'Almè (above) commons in fuchsia and the Lombardy ortho-image [56] in background. 
Secondly, a DEM layer (Figure 13) has been developed in ArcMap and has allowed getting a deep morphological knowledge. Figure 13 shows that the two commons have quite a different morphology and their orthometric height ranges between 234 and $599 \mathrm{~m}$ : Almè, the smaller one, is mostly characterized by flatlands, while Villa d'Almè, the bigger one, shows a more complex landscape, with plain areas and hills.

\section{The Facilities}

As said before, the construction of the Brembana Valley railway required many components, both structural, like bridges and stations, and infrastructural, like the railway tracks.

The aim of the project, described in this paper, has been the survey of two sub-areas where two structural elements can be found: the former Paladina station and the bridge over the Rino river, which are described hereafter.

\subsection{The Former Paladina Station}

The route of the FVB started from the station in Bergamo, which is a testimony of the Liberty style, so popular in those times and also all the other stations along the line where built with the same style.

The station of Paladina (Figure 14) is one of them; it is $9.5 \mathrm{~km}$ far from the station in Bergamo and it is located in the Almè common, which is adjacent to the common of Paladina.

The building, nowadays, shows the signs of abandonment and neglect, but it well reflects the beautiful architectural style of the epoch. It is placed with the longer side fronting the former FVB tracks, now hidden under a thick grass cover. The main damages are to the stucco of the facades and also to all the wooden parts of the roof under the imbrexes, which are now protected with impermeable tarps.

A sketch of the building has been edited in ArcGIS ArcMap [53] and Figure 15 shows it in cyan, over the Lombardy ortho-image [56] background. The surrounding area is industrial and commercial; close to the structure, some factories have been built, because of the strategic position near the county road connecting the town of Bergamo to the Brembana Valley.

\subsection{The Bridge over the Rino River}

The bridge (Figure 16) is located in the Villa d'Almè common, where once flowed the Rino river, which is now buried and from which the name was derived.

The structure is that of an arch bridge and it has been abandoned since 1967; it is one among the first bridges to be built in reinforced concrete, since previously they had been built with iron beams, squared stones or also red bricks (attached with concrete). The bridge span is $27 \mathrm{~m}$ long. Also here a sketch of the structure has been edited in ArcGIS ArcMap [53] and Figure 17 shows it in 
cyan, over the Lombardy ortho-image [56] back-ground. The surrounding area is residential, but there are also some areas which can change their designated use according to the needs of the community.

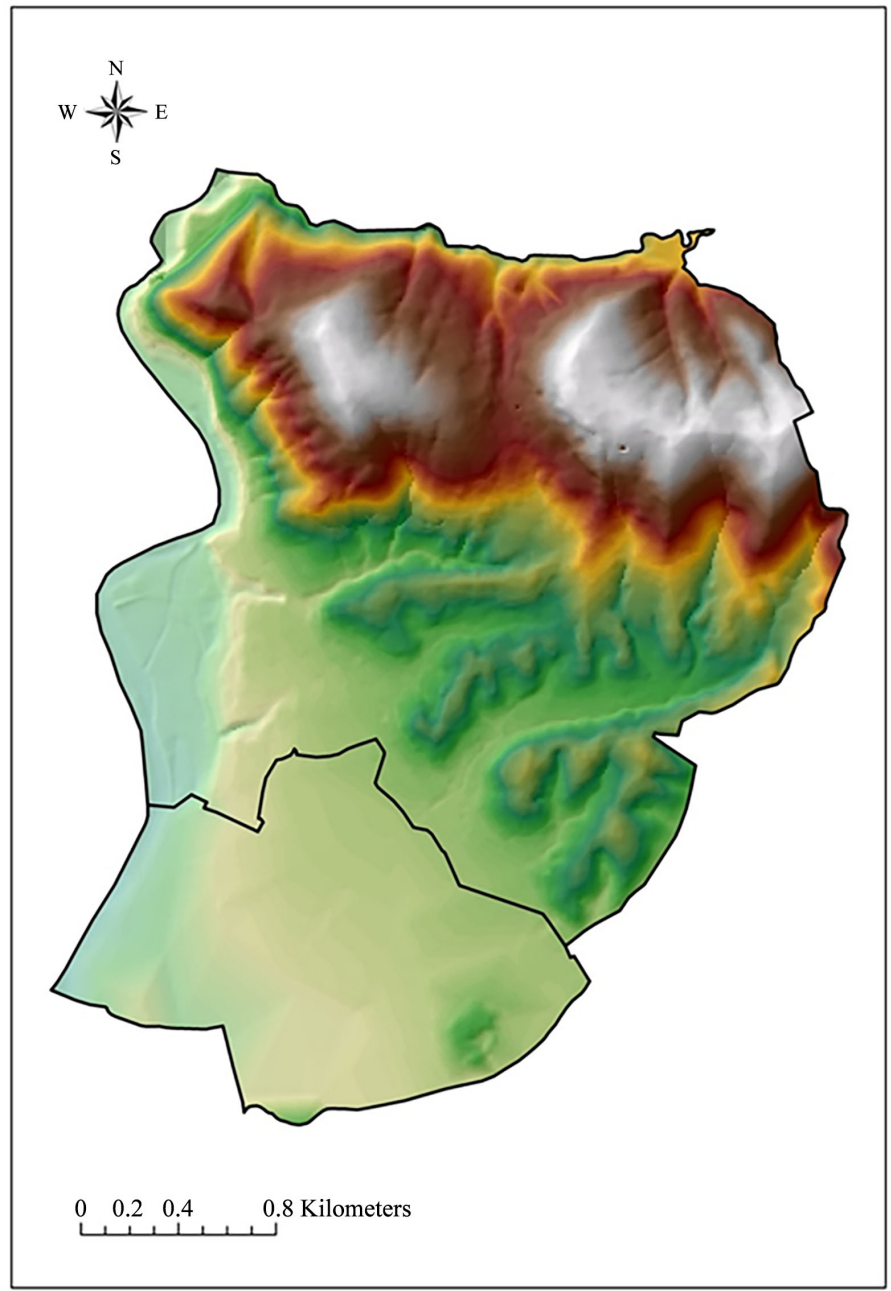

Figure 13. The Almè (lower) and Villa d'Almè (above) commons morphology.

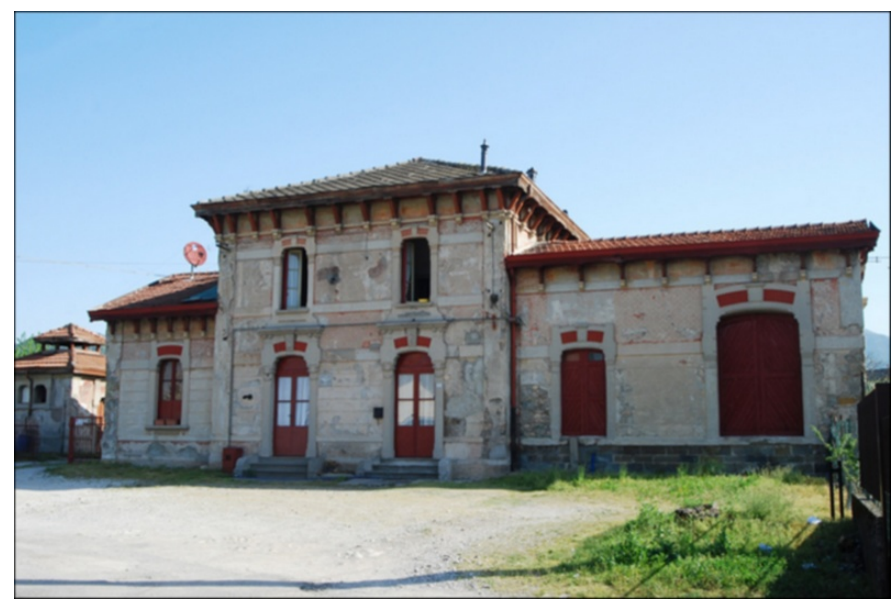

Figure 14. The Liberty style building of the Paladina station [57]. 


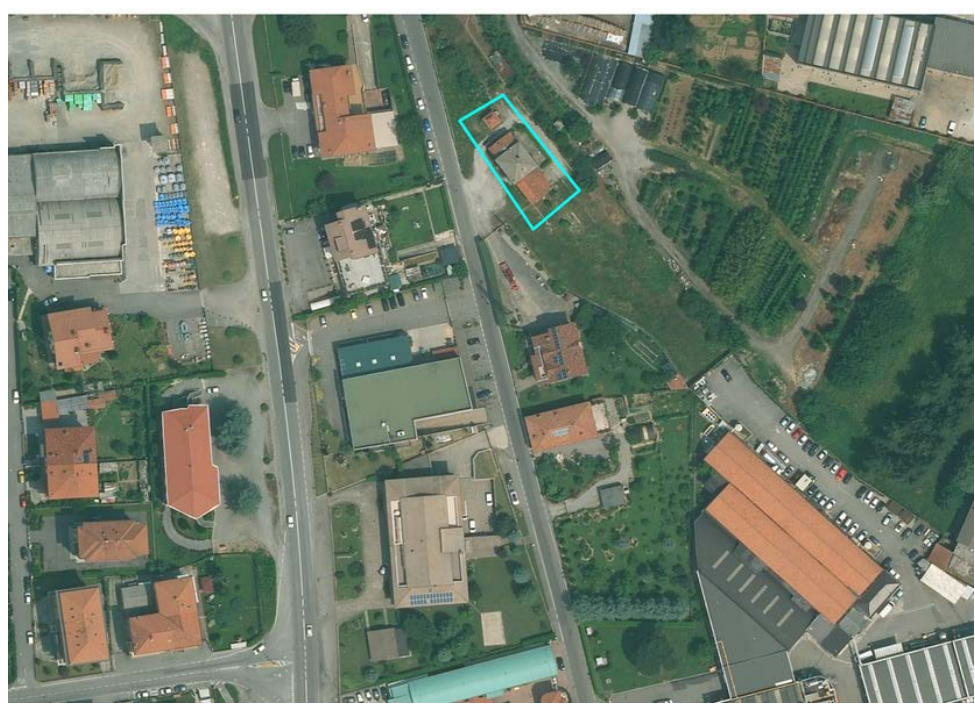

Figure 15. The outline of the former Paladina station.

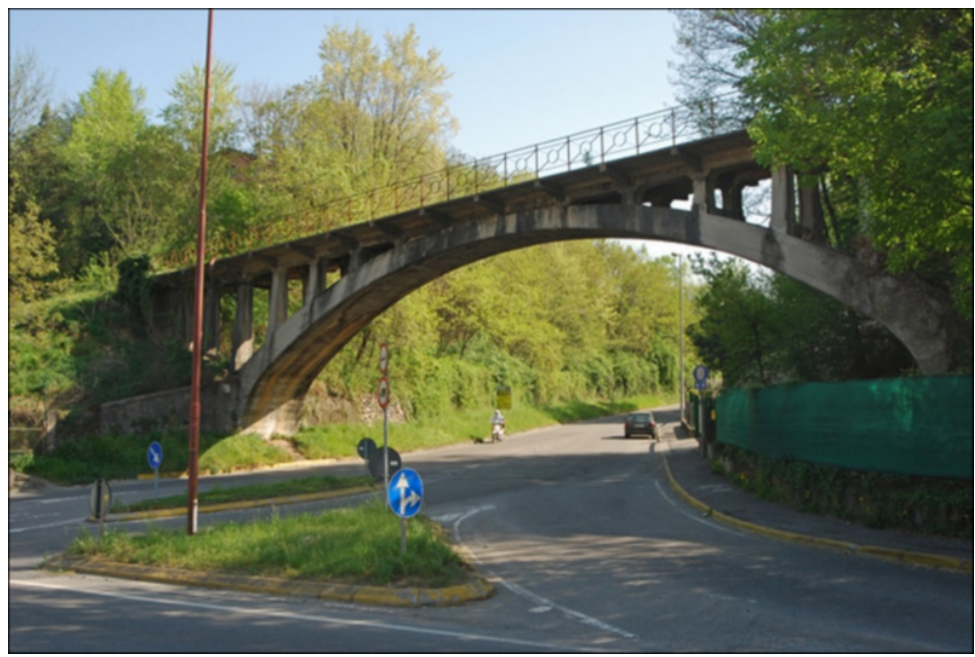

Figure 16. The bridge over the Rino river [57].

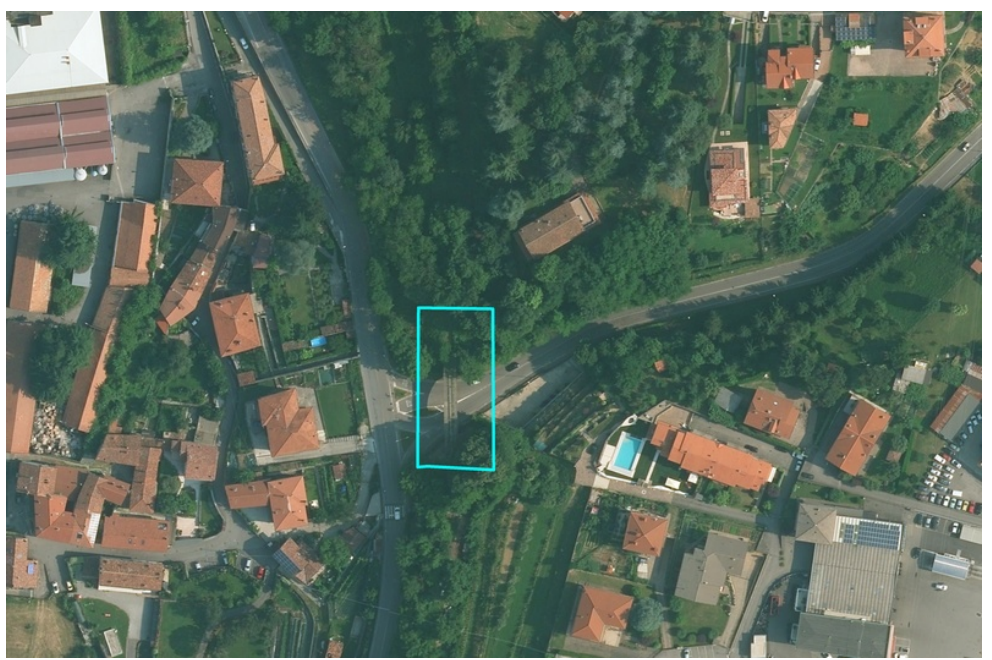

Figure 17. The outline of the bridge over the Rino river. 


\section{The Survey Project}

This step has required a long and thorough analysis to identify the best fitting instruments and technologies for achieving the requested results for the two sub-areas to be surveyed. The new rediscovered interest in the ancient science of photogrammetry has caused a new interest in close range survey, based on images, allowed by the new less expensive digital photo-cameras and the new Computer Vision software packages [17]-[23]. Anyway, the turning point has been the employment of UAVs, simply called drones [58], equipped with digital cameras. They are completely automated and auto piloted, thanks to GNSS positioning devices mounted on board. The great advantage, if compared to the more classic photogrammetric acquisitions (from airplane or satellite), is the possibility to shoot images at a lower relative height and therefore with a higher level of detail. If compared to the active sensors techniques, which have been up to date in the last decades with the employment of laser scanners [10]-[16], UAVs allow an agile, easy and close range acquisition of complex objects, i.e. with not easily visible parts, such as roofs, etc. The two survey techniques, based on active and passive sensors, complete each other and well integrate, also in synergy with the GNSS satellite positioning technologies. In fact, they both have advantages and disadvantages [24] [25] and their combined employment is the way to overcome their bad sides and to allow a data enrichment due to the combination of the good ones [26]-[32]. In this work, the areas are quite wide and constructions, infrastructures, green coverages, etc. can be found. Table 1 lists the two sub-areas main properties.

Table 1. The two sub-areas main characteristics.

\begin{tabular}{|c|c|c|}
\hline \multicolumn{3}{|c|}{ THE TWO SUB-AREAS MAIN PROPERTIES } \\
\hline ID & $\begin{array}{c}\text { Sub-area } 1 \\
\text { (former Paladina station) }\end{array}$ & $\begin{array}{c}\text { Sub-area } 2 \text { (the bridge over } \\
\text { the Rino river) }\end{array}$ \\
\hline Geographic Position & Almè Common & Villa d'Almè Common \\
\hline Land Use Description & $\begin{array}{c}\text { Urban Residential, Industrial and } \\
\text { Rural }\end{array}$ & $\begin{array}{c}\text { Urban Residential and } \\
\text { Industrial }\end{array}$ \\
\hline Property Description & Private and Public Property & Private and Public Property \\
\hline Existing Infrastructures & $\begin{array}{l}\text { Urban roads and Medium Voltage } \\
\text { Electric Lines }\end{array}$ & $\begin{array}{l}\text { Urban roads and Medium } \\
\text { Voltage Electric Lines }\end{array}$ \\
\hline Railway Structures & Former Paladina station & Bridge over the Rino river \\
\hline Planned Stops & Paladina & Villa d'Almè \\
\hline Planned Infrastructures & $\begin{array}{c}\text { SSE } 5 \text { (Railway Electrical } \\
\text { Substation) and Wagons Storage }\end{array}$ & $\begin{array}{c}\text { SSE } 6 \text { (Railway Electrical } \\
\text { Substation) and Wagons Storage }\end{array}$ \\
\hline $\begin{array}{c}\text { Cadastral Particles to be } \\
\text { expropriated }\end{array}$ & Yes & Yes \\
\hline $\begin{array}{l}\text { Est and North Extension of the } \\
\text { survey }\end{array}$ & $220 \mathrm{~m}(\mathrm{E}) \times 180 \mathrm{~m}(\mathrm{~N})$ & $125 \mathrm{~m}(\mathrm{E}) \times 300 \mathrm{~m}(\mathrm{~N})$ \\
\hline $\begin{array}{c}\text { Extension of the area to be } \\
\text { surveyed }\end{array}$ & $39,600 \mathrm{~m}^{2}$ & $37,500 \mathrm{~m}^{2}$ \\
\hline
\end{tabular}


The final choice has been to employ a UAV, with a camera on board, for a wide and above acquisition of the two areas and also a terrestrial laser scanner for the survey of the two structures: the Paladina station and the bridge over the Rino river. In a second step, the union and integration of the dense point clouds [59], surveyed by the two instruments, will provide the so called DSM (Digital Surface Model) which is a thorough metric description of the selected areas, together with natural and built features.

A GNSS positioning has been carried out over selected target points, visible both in the laser and UAVs surveys, which represent the linking elements for the clouds integration, geo-referencing and also information redundancy.

\section{A UAV Flight Plan}

It is important to say that the employment of UAVs is a sensitive issue, because it involves subjects like security, privacy, visual pollution, aerial traffic and the present lack of specifications by the European Community. In Italy, since December 2015, an Amendment by ENAC (Ente Nazionale per l'Aviazione Civile, i.e. National Institution for Civil Aviation) [60] has been promulgated for the Regulation of Aerial Remote Pilot vehicles [61].

A UAVsurvey with cameras on board is a passive automated technique where sensors receive the light emitted by the objects and provide images which need to be managed to achieve their spatial coordinates, besides their texture description.

It has the same requisites of close range photogrammetry, which means that three steps must be followed:

- acquisition, based on the choice of the cameras, of the shots and the survey technique;

- internal and external bearing, which means the camera calibration and the images triangulation;

- photogrammetric plotting, so as to achieve point clouds, 3D models and texture mapping.

In respect with these requirements, a flight plan was compiled and the selected UAV programmed, so as to achieve the proper coverage for the surveying area. In particular, the adjacent snapshots were overlapped about $70 \%-80 \%$ both in the longitudinal and transversal directions, flying at the suitable relative height [62].

It needs to be said that the final 3D model needs to be geo-referenced and for this reason an indirect solution is to select some control points (GCP - Ground Control Points), well distributed over the selected area, with coordinates usually acquired via topographic and GNSS instruments and materialized with targets or well identifiable with anthropic or natural elements.

Figure 18 and Figure 19 show the flight plan for the MicroGeo AeromaX6 [7] which was employed for a nadir flight over the station and also over the bridge sub-areas and which was guided by a certified technician. 


\section{The on the Field Survey}

Since the two sub-areas to be surveyed are quite wide (little less than 4 hectares each) and they are characterized by constructions, vegetation, street infrastructures and other artefacts, the natural choice is a terrestrial (active) and aerial (passive) survey. Besides, according to the need of gathering in a unique multiresolution 3D model the products of different survey techniques and then to geo-reference it, also some targets have been positioned on selected places and surveyed with GNSS instruments. This complex survey (terrestrial laser scanner, UAV and GNSS) has been possible thanks to the contribution of teams from different companies [5] [6] [7] [8].

The instruments adopted, and provided by the teams [5] [6] [7] [8], are:

- Z+F IMAGER ${ }^{\infty} 5010$ [63] 3D terrestrial laser scanner, with a mounted Nikon D7000 reflex photo camera [64], surveyor Engineer Begnis [5] [6];

- MicroGeo AeromaX6 UAV [7] (take-off weight range 3.85 - $4.1 \mathrm{~kg}$ ) with a DJI FC550 photo camera [65], survey by MicroGeo [7];

- GNSS SOKKIA GRX2 receiver [66], surveyor Architect Merelli [8];

- Leica D5 Disto laser range marker by Leica Geosystems [67], Arch. Merelli [8].

Once the instruments have been selected, it is important to correctly select the GCP on the ground to be surveyed with the GNSS receivers (and to be well identifiable by above) and the final choice is described hereafter:

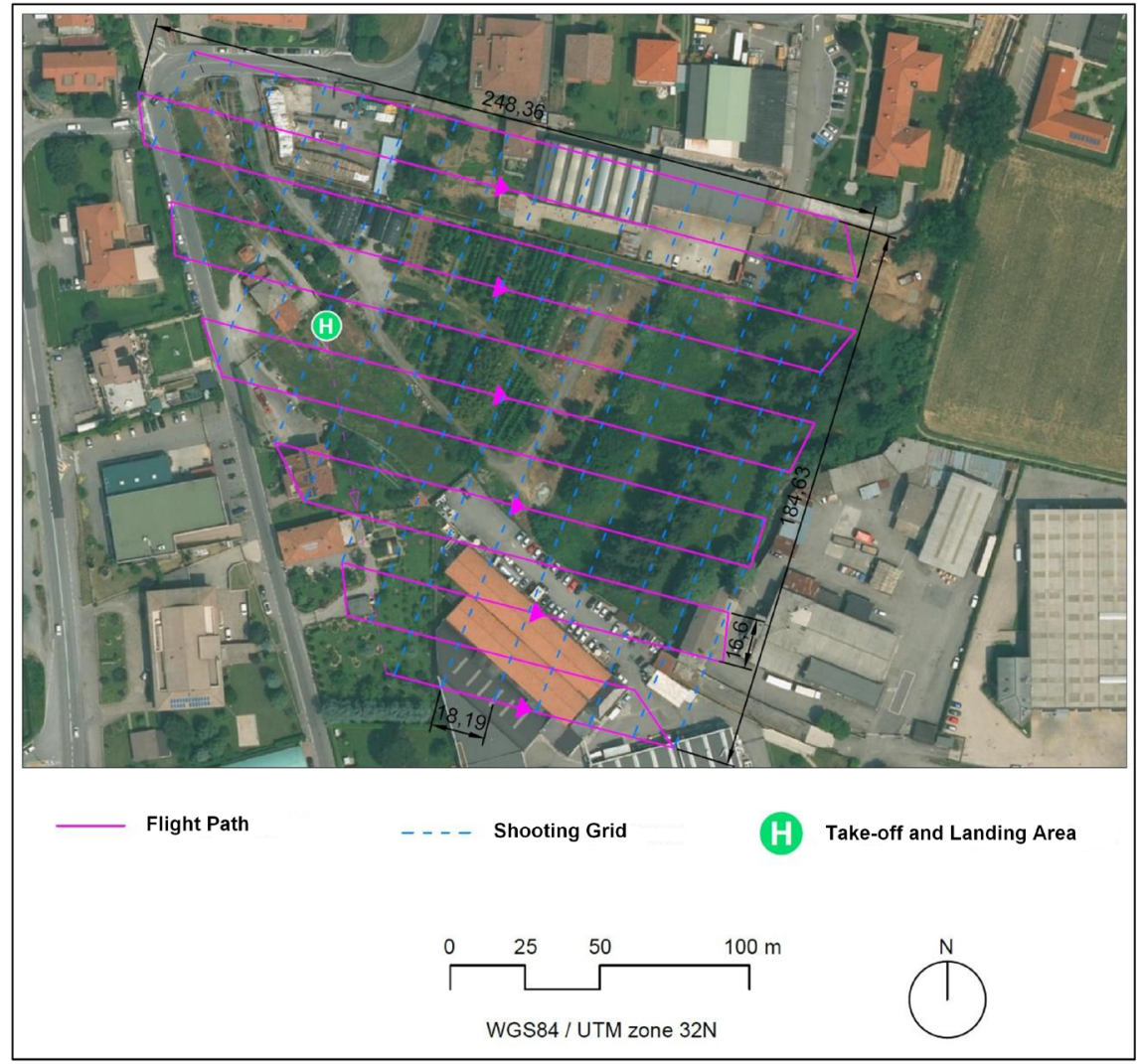

Figure 18. The Aeroma X6 flight plan of the sub-area 1 (former Paladina station). 


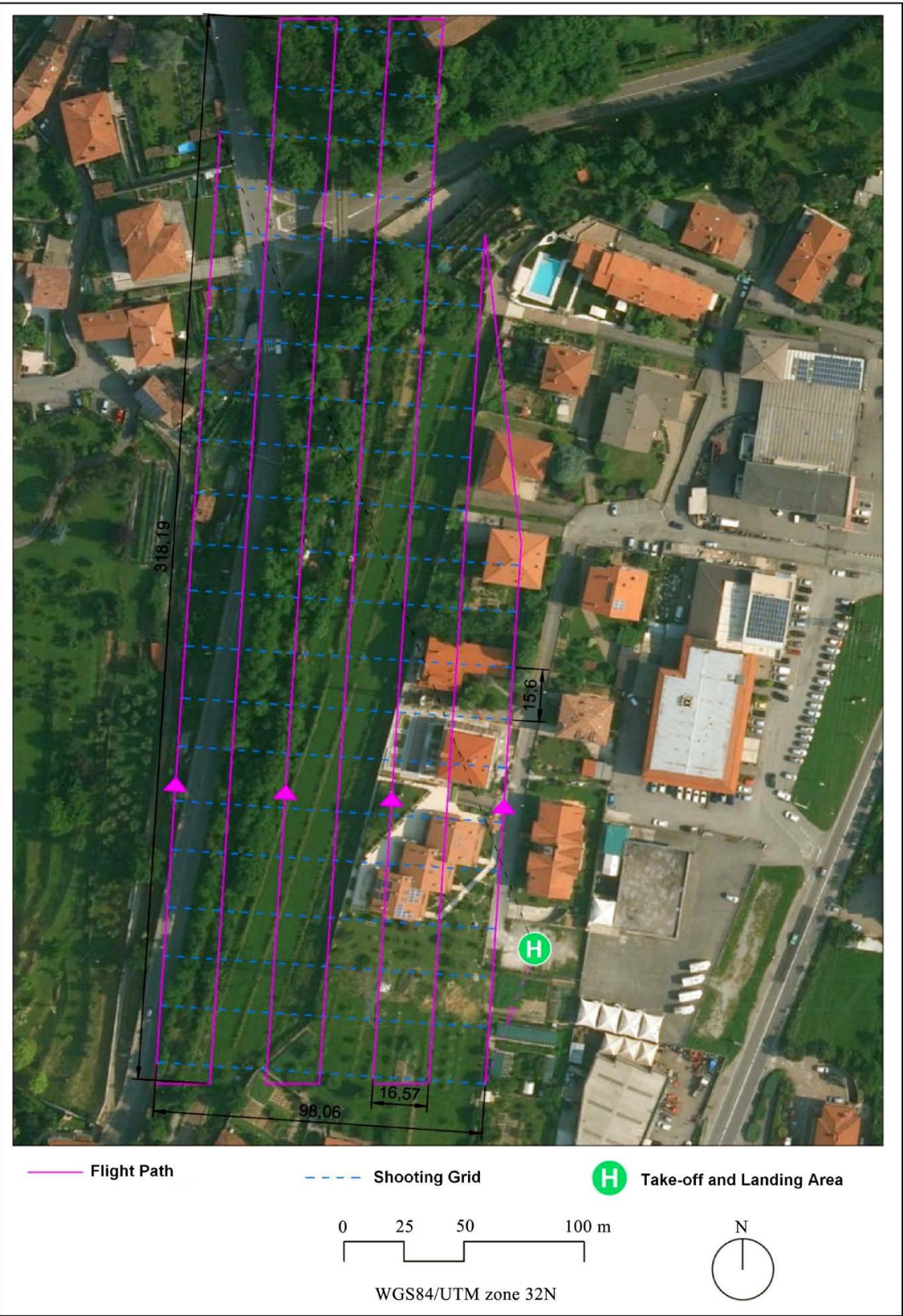

Figure 19. The Aeroma X6 flight plan of the sub-area 2 (the bridge over the Rino river).

- four A3 paper artificial targets $\left(25 \times 25 \mathrm{~cm}^{2}\right)$ have been placed close to the Paladina station;

- other four have been placed near the bridge over the Rino river;

- four numbered crosses have been painted on the tarmac so as to cover the area surrounding the Paladina station;

- thirteen numbered crosses have been painted on the tarmac so as to cover the area surrounding the bridge over the Rino river.

The paper targets will provide a higher precision than the painted ones, but they all are needed for the photogrammetric model dimensioning and bearing, for the laser scanner clouds alignment and for the dense clouds merging. 
Figure 20 and Figure 21 show the targets in the two selected sub-areas, displayed according to their acquired GNSS position, over a Basemap layer in ArcMap. The paper targets are the points identified with the letter $\mathrm{T}$, while the painted crosses are identified with their number.

The laser scanner acquisitions of the Paladina station and of the bridge have been performed at the same time of the GCP survey through the GNSS technique.

\section{The Processing Step}

Since the survey has involved different instruments, i.e. laser scanner, UAV and GNSS receivers, it has been necessary to use different software packages for the processing step, so as to manage big amounts of data in different formats. For this reason, two software packages (license educational) have been adopted for the $3 \mathrm{D}$ model reconstruction:

- Agisoft PhotoScan Professional (1.4.0 release) by Agisoft LLC [68], for image based reconstructions [69] [70];

- Cyclone full (9.1.6 and 9.2.1 releases) by Leica Geosystems [67], for the laser scanning model and for the matching of all the different acquired data [71] [72].

The first package, in fact, doesn't allow to extract 3D data from blocks of images and, for this reason, the second one has been adopted also to perform this task. The final purpose is to achieve a 3D model, through dense point clouds, to be then processed so as to extract the required raster and vector products, previously described.

The data processing has been performed following the steps shortly described hereafter:

- GNSS coordinates processing and following transformation in the WGS84 UTM Zone $32 \mathrm{~N}$ reference system, providing what has been previously illustrated in Figure 20 and Figure 21;

- processing of the image aerial block (acquired over the two sub-areas), by means of the Agisoft PhotoScan Package [68], so as to extract photo dense point clouds and then the final 3D photo-model;

- processing of the laser scanner point clouds, of the station and of the bridge structures, through the software Leica Cyclone [67], providing the two 3D models. Panoramic images have been then superimposed, providing the clouds colour;

- the final geo-referenced 3D model has been performed with the Cyclone Package [67]; all the acquired point clouds need to be geo-referenced in the same WGS84 UTM Zone 32N reference system, through the surveyed GNSS GCP, so as to be managed together. In fact, the clouds are both laser scanner products and a UAV close photogrammetry ones. The clouds have been managed together in Cyclone [67]; in Figure 22 and Figure 23 it is well illustrated the contribution of the different clouds involved. 


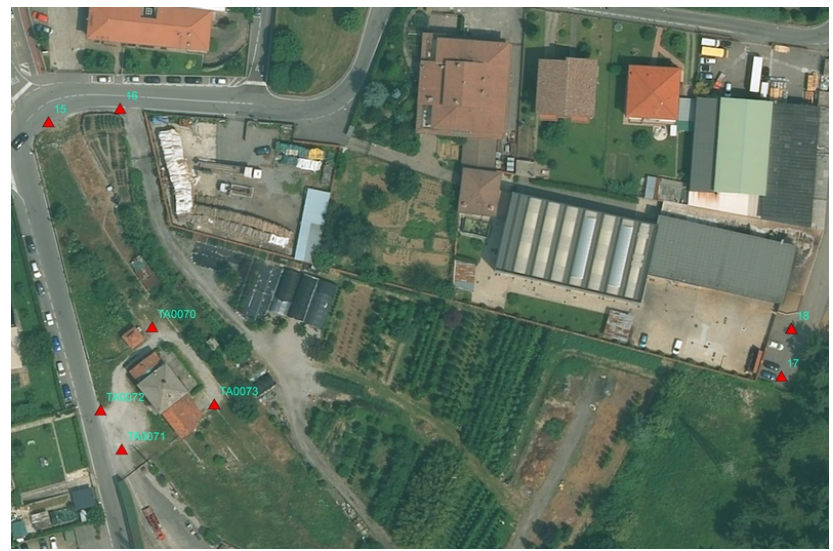

Figure 20. The GCP for the sub-area1 site.

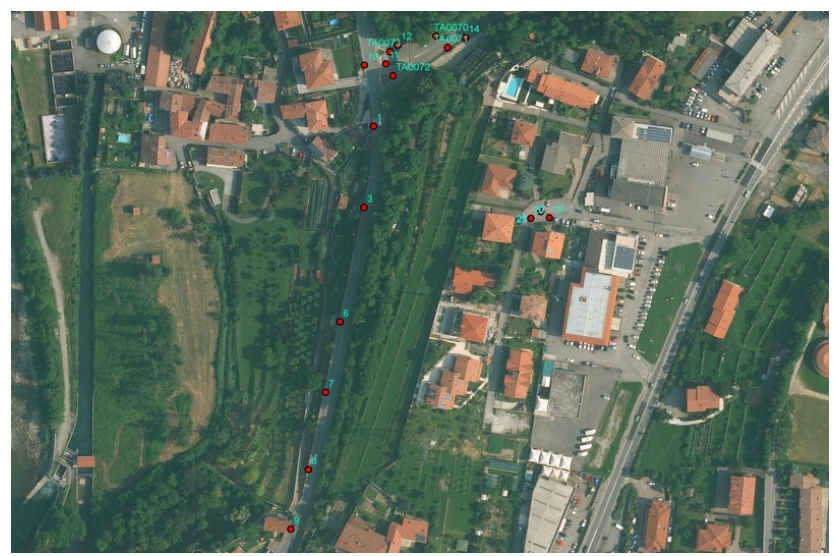

Figure 21. The GCP for the sub-area 2 site.

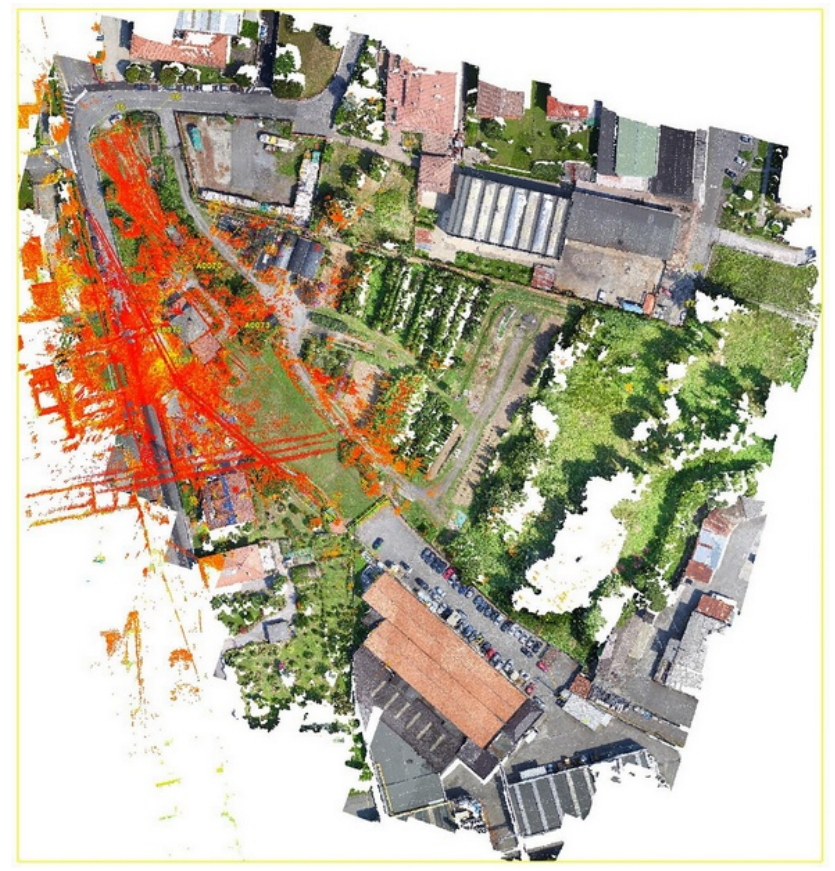

Figure 22. The two integrated clouds of the sub-area 1 achieved from the terrestrial laser scanner survey and the UAV survey. 


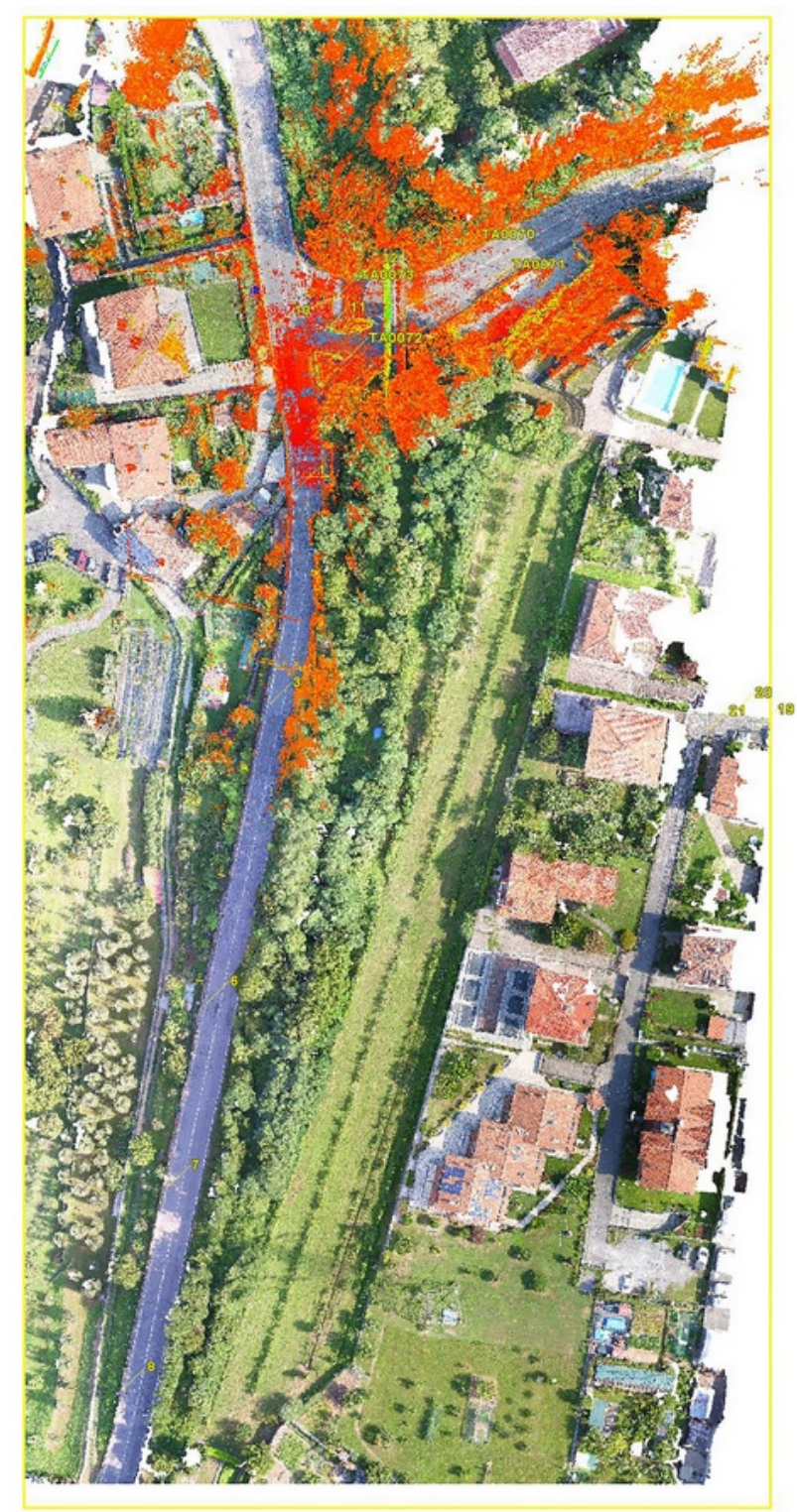

Figure 23. The two integrated clouds of the sub-area 2 achieved from the terrestrial laser scanner survey and the UAV survey.

\section{Further Processing, GIS Analyses, Acquired Products and Some Comments}

The last step has been to manage the point clouds, achieved through the integration of the different survey techniques, so as to provide vector and raster products, according to E.T.S. [4] and the project team [5, 6, 7, 8 and the Geomatics group] requirements, and which need to be all geo-referenced in the WGS84 UTM Zone $32 \mathrm{~N}$ reference system. The first four are related to the description of the morphology of the terrain and the urban areas together in the same DSM model [73], while the last two are strictly connected to the two structures in the selected sub-areas, i.e. the former Paladina station and the bridge over the Rino river: 
- RGB geo-referenced ortho-image;

- classification of the point clouds and the surfaces;

- DEM, DTM and DSM layers;

- terrain contour lines at $1 \mathrm{~m}$ interval;

- layouts, overviews and sections;

- orthographic projections of the overviews.

The software packages adopted are: Leica Cyclone [67], Agisoft PhotoScan Professional [68], Autodesk [74] ReCap Pro and ReCap Photo, Faro Scene [75], MeshLab [76], CloudCompare [77] and Autodesk AutoCAD [78].

It is also useful to shortly remind the difference among the following terrain models [79]:

- DTM (Digital Terrain Model) describes the terrain morphology without vegetation and anthropic elements;

- DSM (Digital Surface Model) describes the morphology of the terrain morphology together with the vegetation and all the natural and anthropic elements;

- DEM (Digital Elevation Model) is a general elevation model, the same as DTM.

The classification step has been accomplished according to the selected attributes: ground, low-medium-high vegetation, buildings, street surface, bridge decks, water, unclassified, noise, etc., as it is well illustrated in Figure 24 and Figure 25. They have been managed directly in the Agisoft PhotoScan [68] software, with the aid of AutoCAD [78], which automatically provides the DSM classification according to the point density and other criteria, while other software packages [80] allow doing this by simply analyzing the color information. Anyway, if necessary, it is useful to integrate the results with the naked eye. The areas, defined as unclassified, are those where it is impossible to recognize the nature of the existing objects.

\section{Analysis of the Point Model Reconstructed for the Two Test Sub-Areas}

The final point model, for each sub-area, has been provided by joining the data acquired with laser scanner and UAV photogrammetric techniques.

Table 2 shows the spatial precision of the just said datasets and the reliability of the GNSS survey for the GCP collection which is well distributed on the ground of the two test areas. These points have been employed for the bundle adjustment of the block of aerial images and laser scanner data, collected during the survey.

By looking at the table, it is possible to see that the RTK satellite measurements have reached planimetric $(\mathrm{E}, \mathrm{N})$ precisions of the centimeter and half decimeter in height $(\mathrm{H})$, due to the more uncertain contribution of the orthometric height with the geoid undulation. On the other hand, the laser scanning shows centimeter precision, homogenous for the three coordinates, while the UAV photogrammetric has half decimeter planimetric values and about two decime- 
ters for height values; this is due to a slightly turbulent and windy meteorological condition during the survey.

The metric quality of the joint point model can be checked through the residuals estimated on Check Points (CP), selected among the GCP acquired with GNSS satellite technique, which have not been employed in the least squares block adjustment.

Table 3 illustrates the just said residuals for the $\mathrm{CP}$ of the sub-area 2. The planimetric results are of about few centimetres while they rise up to the decimetre for higher or of more complex morphology zones of the reconstructed model. Anyway, the values show to be suitable at the planned restitution scales which are 1:500 and 1:1000, for the territorial areas; they are also acceptable for the $1: 200$ artefact details.

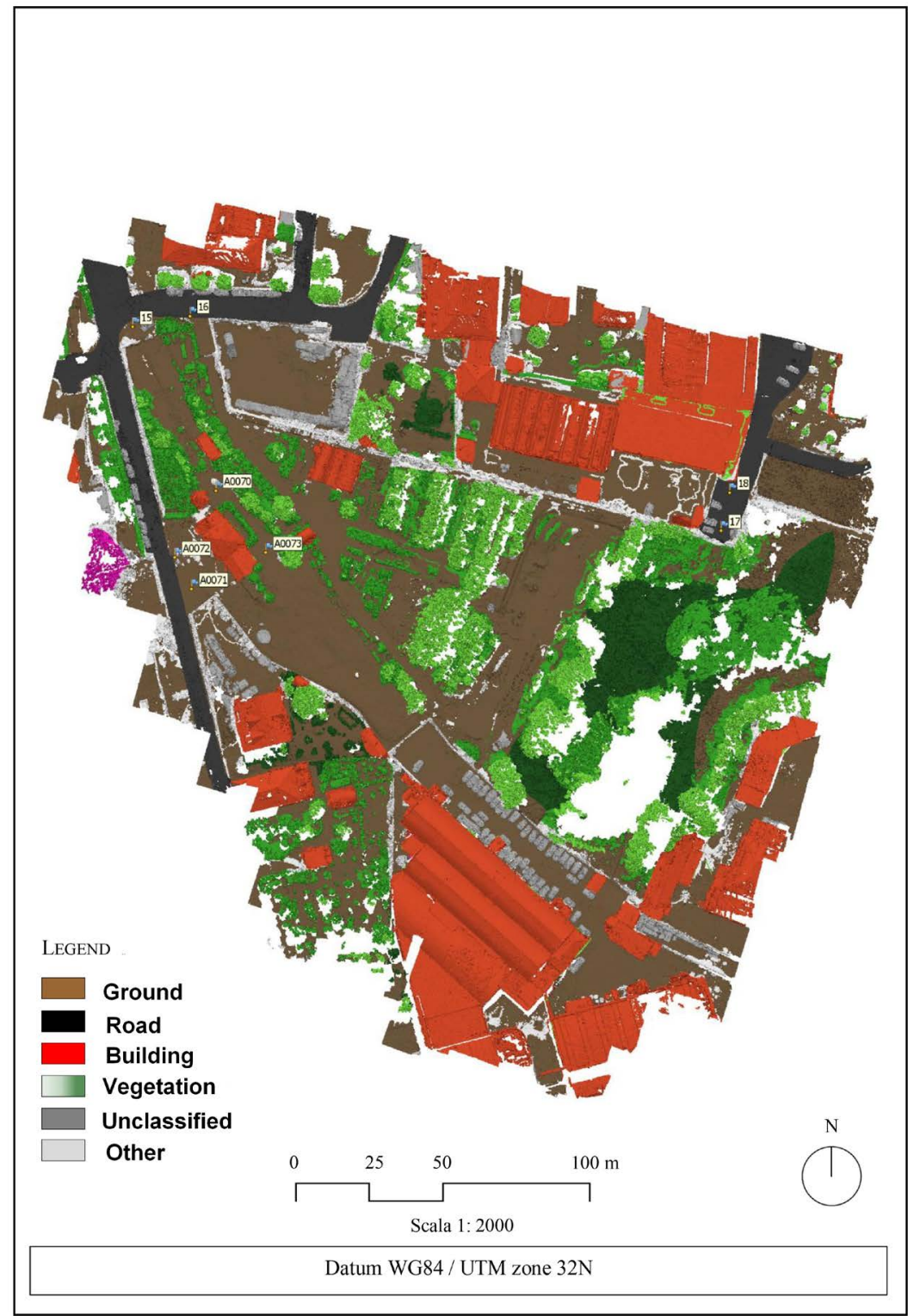

Figure 24. The classification of the sub-area 1. 


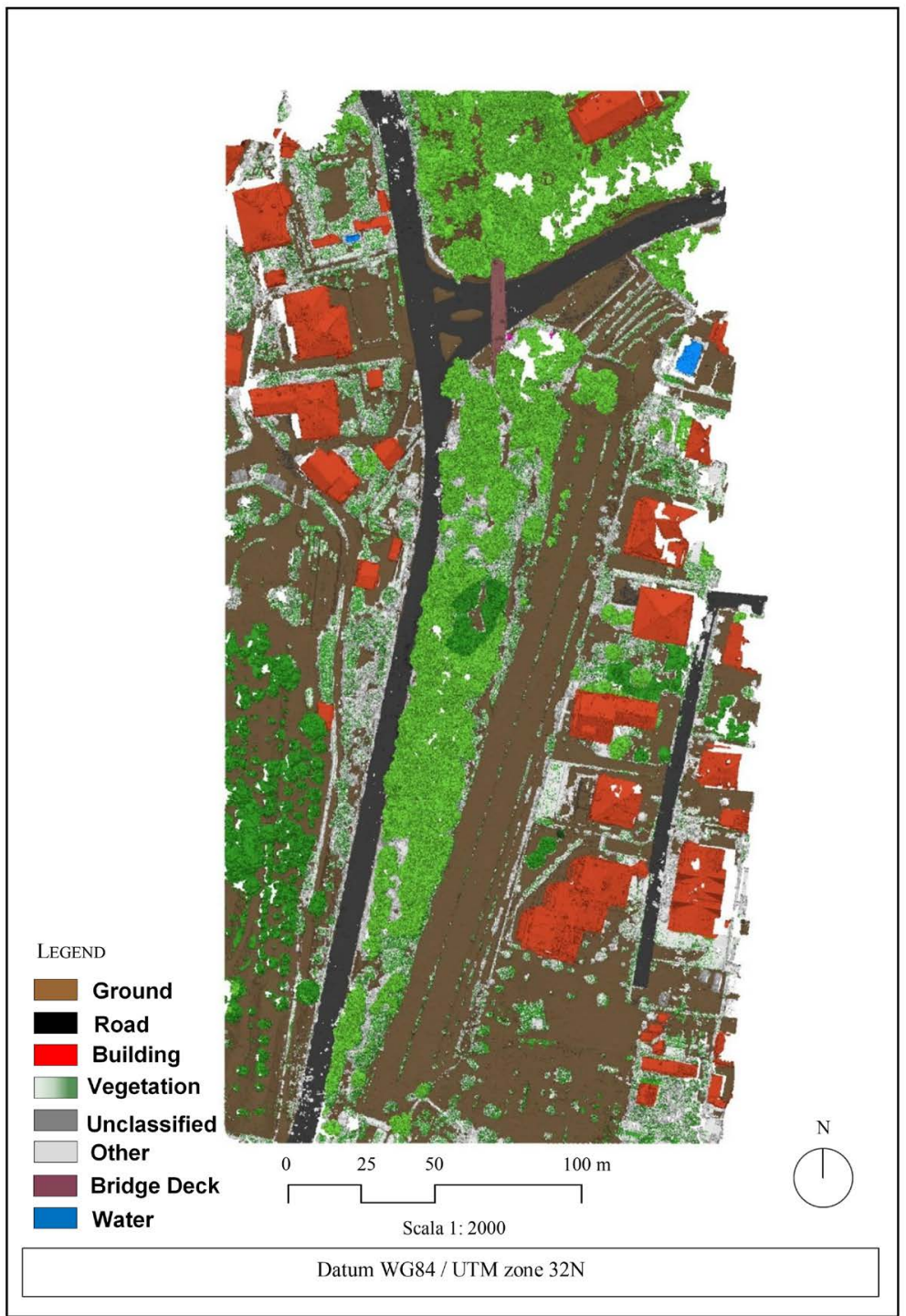

Figure 25. The classification of the sub-area 2.

Table 2. Summary of the point clouds errors.

\begin{tabular}{cccc}
\hline \multicolumn{4}{c}{ SURVEY ACCURACY } \\
\hline Survey technique & Coordinates & SUB-AREA 1 & SUB-AREA 2 \\
\hline E & $\pm 10 \mathrm{~mm}$ & $\pm 10 \mathrm{~mm}$ \\
GNSS & N & $\pm 10 \mathrm{~mm}$ & $\pm 10 \mathrm{~mm}$ \\
H & $\pm 50 \mathrm{~mm}$ & $\pm 50 \mathrm{~mm}$ \\
Laser Scanner & E & $\pm 10 \mathrm{~mm}$ & $\pm 10 \mathrm{~mm}$ \\
N & $\pm 10 \mathrm{~mm}$ & $\pm 10 \mathrm{~mm}$ \\
Close range & H & $\pm 10 \mathrm{~mm}$ & $\pm 10 \mathrm{~mm}$ \\
photogrammetry & E & $\pm 55 \mathrm{~mm}$ & $\pm 40 \mathrm{~mm}$ \\
& N & $\pm 70 \mathrm{~mm}$ & $\pm 40 \mathrm{~mm}$ \\
& H & $\pm 200 \mathrm{~mm}$ & $\pm 240 \mathrm{~mm}$ \\
\hline
\end{tabular}


Table 3. Residuals of some selected Check Points (CP).

\begin{tabular}{cccc}
\hline \multicolumn{4}{c}{ CP RESIDUALS } \\
\hline ID CP & $\Delta \mathrm{E}[\mathrm{cm}]$ & $\Delta \mathrm{N}[\mathrm{cm}]$ & $\Delta \mathrm{H}[\mathrm{cm}]$ \\
\hline 11 & 3.60973 & 2.54393 & 40.7967 \\
7 & -2.7783 & 3.93005 & -9.09833 \\
20 & 2.86923 & -1.18056 & 0.563765 \\
\hline
\end{tabular}

However, the acquired results suggest a more rigorous choice in the UAV device, both for resistance to the wind and for stability in the flight height, especially for the not nadir aerial shooting.

The final hybrid model, provided by the integration of terrestrial and aerial datasets, shows a more detailed description also for anthropic elements and hidden parts, such as the bridge intradoses in the sub-area 2.

What has been just said testifies the satisfactory test results and their accordance to the attended ones, defined in the survey project.

\section{Final Remarks}

The work presented here, consists in a preliminary test (carried out by some survey teams [5] [6] [7] [8] and the Geomatics group at the University of Bergamo, with the agreement of E.T.S. [4]) to evaluate the advantages and disadvantages related to the employment of an integrated survey approach, based on $\mathrm{UAV}$, laser scanner and GNSS techniques, over two (meaningful) land sub-areas involved in the project for the construction of a modern light tramway along the former Brembana Valley railway route. Costs, duration and also the different problems regarding the integration of different data sets, in order to create an effective final 3D model, are analyzed.

It is important to stress that this new approach allows achieving a more complete and less time demanding documenting intervention; anyway, the results concerning costs and duration are not presented here, since they will be object of further analyses.

Some important information about the different software packages involved has stressed that it is a complex procedure to process the $3 \mathrm{D}$ point clouds, which needs time and many steps, so as to accomplish the required final model.

Also the classification step, previously described, is not completely automated and easy to perform, since it still requires the manual involvement of a technician.

Anyway, it can be said that the acquired results are quite satisfactory and all E.T.S. [4] and the project team [5] [6] [7] [8] and the Geomatics group] requirements have been thoroughly fulfilled; they will surely provide a helpful suggestion so as to project the future intervention of the former Val Brembana railway.

According to what just said, the paper describes the different steps accom- 
plished, so as to achieve the useful 3D model.

A thorough analysis of the reached precisions testifies that the results are in satisfactory agreement with the decisions made in the survey project.

The experience has demonstrated the helpful contribution of the recent UAV technologies, together with laser scanning and image-based surveys; this is certainly a revolutionary process useful in many applications, such as spatial reconstructions, analyses of human-made objects (buildings and infrastructures) and automation. The certain advantages concern the simplification and the enhancement of the survey procedure: however, all this will never overcome the importance of both a rigorous training and the professional experience of the technicians.

\section{Acknowledgements}

Many thanks to Professor Luigi Colombo, for his contribution to the project, sound knowledge in the field of geomatics and useful advice.

Thanks are due to the GIS course students, at the University of Bergamo (Engineering), Juan Azzola and Valentina Buzzanga for the work developed in their thesis.

Also thanks to Engineer Riccardo Begnis, Scan2BIM [5] and R+TB [6] for the assistance in the project, laser scanner acquisition and data processing with the students, to MicroGeo Srl [7] for the instruments provided and the photogrammetric UAV acquisition and to the Architect Mario Merelli [8] for his professional role and contribution in the GNSS survey.

Also thanks are due to the Bergamo Valleys Railways Association [42] and its president Alessandro Gervasoni for the useful documentation provided and also to the E.T.S. [4] Company which has set the first step towards the realization of this railway project.

\section{Conflicts of Interest}

The author declares no conflicts of interest regarding the publication of this paper.

\section{References}

[1] http://www.teb.bergamo.it/it/teb/progetti-/linea-t2-bergamo-villa-dalm-1

[2] https://www.atb.bergamo.it/it

[3] http://www.teb.bergamo.it/it

[4] http://www.etseng.it/

[5] http://www.scan2bim.it/

[6] http://rtba.it/

[7] http://www.microgeo.it/it/default.aspx

[8] Architect Merelli, M. Pianificatore Territoriale, Via Andrea Fantoni, 63-Alzano Lombardo, Bergamo. https://linkedin.com/in/mario-merelli-08a705170/

[9] http://www.lavocedellevalli.it/cronaca/articolo/tram-bergamo-villa-dalme-firmatoprotocollo-dintesa-ci-vogliono-145-milioni 
[10] Balsa-Barreiro, J. and Lerma, J.L. (2006) Aplicación de la tecnología del láser escáner aerotransportado (ALS) a la generación de modelos digitales urbanos. Topografia y Cartografia, 23, 3-8.

[11] Pirotti, F., Guarnieri, A. and Vettore, A. (2013) State of the Art of Ground and Aerial Laser Scanning Technologies for High-Resolution Topography of the Earth Surface. European Journal of Remote Sensing, 46, 66-78. https://doi.org/10.5721/EuJRS20134605

[12] Puente, I., González-Jorge, H., Martínez-Sánchez, J. and Arias, P. (2013) Review of Mobile Mapping and Surveying Technologies. Measurement, 46, 2127-2145. https://doi.org/10.1016/j.measurement.2013.03.006

[13] Bostrom, G., Fiocco, M., Goncalves, J. and Sequeira, V. (2006) Urban 3D Modeling Using Terrestrial Laser Scanners. International Archives of Photogrammetry and Remote Sensing. Dresden, Germany. XXXVI, 279-284.

[14] Tang, T., Zhao, W., Gong, H., Zhang, A., Pan, J. and Liu, Z. (2008) Terrestrial Laser Scan Survey and 3D TIN Model Construction of Urban Buildings in a Geospatial Database. Geocarto International, 23, 259-272. https://doi.org/10.1080/10106040801915917

[15] Heritage, G. and Large, A. (2009) Laser Scanning for the Environmental Sciences. Wiley Blackwell, London, 288. https://doi.org/10.1002/9781444311952

[16] Pfeifer, N. and Briese, C. (2007) Laser Scanning: Principles and Applications. GeoSiberia 2007-International Exhibition and Scientific Congress, Nowosibirsk, Russia, April 2007, 93-112. https://doi.org/10.3997/2214-4609.201403279

[17] Haala, N., Rothermel, M. and Cavegn, S. (2015) Extracting 3D Urban Models from Oblique Aerial Images. Proceedings of Joint Urban Remote Sensing Event (JURSE), Lausanne, Switzerland, 30 March-1 April 2015, 1-4. https://doi.org/10.1109/JURSE.2015.7120479

[18] Shashi, M. and Jain, K. (2007) Use of Photogrammetry in 3D Modeling and Visualization of Buildings. ARPN Journal of Engineering and Applied Sciences, 2, 37-40.

[19] Luhmann, T., Robson, S., Kyle, S. and Hartley, I. (2006) Close Range Photogrammetry: Principles, Techniques and Applications. Whittles, Dunbeath. 528 p.

[20] Barazzetti, L., Remondino, F. and Scaioni, M. (2011) Automated and Accurate Orientation of Complex Image Sequences. International Archives of the Photogrammetry, Remote Sensing and Spatial Information Sciences, 38, 277-284.

[21] Rothermel, M., Wenzel, K., Fritsch, D. and Haala, N. (2012) Sure: Photogrammetric Surface Reconstruction from Imagery. Proceedings LC3D Workshop, Berlin, December 2012, 1-9.

[22] Wenzel, K., Rothermel, M., Fritsch, D. and Haala, N. (2013) Image Acquisition and Model Selection for Multi-View Stereo. International Archives of the Photogrammetry, Remote Sensing and Spatial Information Sciences, 40, 251-258.

[23] Matthews, A. (2008) Aerial and Close-Range Photogrammetric Technology: Providing Resource Documentation, Interpretation, and Preservation. Technical Note 428 , U.S. Department of the Interior, Bureau of Land Management, National Operations Center, Denver, $42 \mathrm{p}$.

[24] Sahin, C., Alkis, A., Ergun, B., Kulur, S., Batuk, F. and Kilic, A. (2012) Producing 3D City Model with the Combined Photogrammetric and Laser Scanner Data in the Example of Taksim Cumhuriyet Square. Optics and Lasers in Engineering, 50, 1844-1853. https://doi.org/10.1016/j.optlaseng.2012.05.019

[25] Fowler, A. and Kadatskiy, V. (2011) Accuracy and Error Assessment of Terrestrial, 
Mobile and Airborne Lidar. Annual Conference Milwaukee, Milwaukee, Wisconsin, 1-5 May 2011.

[26] Balsa-Barreiro, J. and Fritsch, D. (2018) Generation of Visually Aesthetic and Detailed 3D Models of Historical Cities by Using Laser Scanning and Digital Photogrammetry. Digital Applications, Archaeology and Cultural Heritage, 8, 57-64. https://doi.org/10.1016/j.daach.2017.12.001

[27] Hammoudi, K., Dornaika, F. and Paparoditis, N. (2011) Generating Virtual 3D Model of Urban Street Façades by Fusing Terrestrial Multi-Source Data. 7 th International Conference on Intelligent Environments, Nottingham, 25-28 July 2011, 330-333.

[28] Oniga, E. (2012) Comparative Study on Methods for 3D Modelling of Urban Areas. International Archives of the Photogrammetry, Remote Sensing and Spatial Information Sciences, Melbourne, 25 August-1 September 2012, 155-160.

https://doi.org/10.5194/isprsarchives-XXXIX-B6-155-2012

[29] Bayram, B., Nemli, G., Özkan, T., Oflaz, O., Kankotan, B. and Çetin, I. (2015) Comparison of Laser Scanning and Photogrammetry and Their Use for Digital Recording of Cultural Monument Case Study: Byzantine Land Walls-Istanbul. ISPRS Annals of Photogrammetry, Remote Sensing and Spatial Information Sciences, Taipei, 31 August-4 September 2015, 17-24. https://doi.org/10.5194/isprsannals-II-5-W3-17-2015

[30] Koch, M. and Kaheler, M. (2009) Combining 3D Laser-Scanning and Close-Range Photogrammetry: An Approach to Exploit the Strength of Both Methods. Proceedings of the 37 th International Conference on Computer Applications to Archaeology, Williamsburg, 22-26 March 2009, 1-7.

[31] Grussenmeyer, P., Landes, T., Voegtle, T. and Ringle, K. (2008) Comparison Methods of Terrestrial Laser Scanning, Photogrammetry and Tacheometry Data for Recording of Cultural Heritage Buildings. International Archives of Photogrammetry, Remote Sensing and Spatial Information Sciences, 37, 213-218.

[32] Han, L., Chong, Y., Li, Y. and Fritsch, D. (2014) 3D Reconstruction by Combining Terrestrial Laser Scanner Data and Photogrammetric Images. Proceedings of Asian Association on Remote Sensing, Nay Pyi Taw, 27-31 October 2014.

[33] http://www.vallebrembana.com/

[34] http://www.provincia.bergamo.it

[35] http://www.sanpellegrinoterme.gov.it/turismo/curiosita/la-ferrovia/

[36] https://it.wikipedia.org/wiki/San_Pellegrino_Terme

[37] https://www.sanpellegrino.com

[38] http://www.sanpellegrinoterme.gov.it/turismo/il-liberty/

[39] https://doc.studenti.it/vedi_tutto/index.php?h=62e2b6ca\&pag=1

[40] http://www.italyheritage.com/genealogy/surnames/regions/lombardia/

[41] http://www.italoamericano.org/story/2016-8-4/san-pellegrino

[42] https://it-it.facebook.com/ferrovievallibergamasche/

[43] Leopardi, G., Martinelli, L. and Ferruggia, C. (2005) Treni e tramvie della bergamasca. Ferrari Editrice.

[44] Gualteroni Avv, A. (1926) Il prolungamento della ferrovia elettrica di Valle Brembana. http://www.valbrembanaweb.it/alta-valle-brembana/pdf/01.pdf

[45] AA. VV. (2006) Il sogno brembano: Industrializzazione e progresso sociale nella Valle Brembana del primo novecento. Centro storico culturale Valle Brembana 
Corponove Editrice, $560 \mathrm{p}$.

[46] Oberti, D. (2017) Le ferrovie perdute, Associazione Ferrovia Valle Brembana, Equa Editrice, $319 \mathrm{p}$.

[47] http://www.bergamopost.it/cambiare-rotta/la-soluzione-per-entrare-bergamo-la-fer rovia-della-valle-brembana/

[48] https://www.pieroweb.com/eventi/museovalle/ferroviavb/immagini.htm

[49] http://www.lavocedellevalli.it/cronaca/articolo/ferrovie-perdute-il-ricordo-del-tren o-in-val-brembana-diventa-rimpianto

[50] https://www.ecodibergamo.it/stories/valle-brembana/treno-della-valbrembana-qua nti-ricordi50-anni-fa-lultima-corsa-foto-e-video_1177183_11/

[51] http://www.comune.alme.bg.it/hh/index.php

[52] http://www.comune.villadalme.bg.it/

[53] https://www.esri.com/en-us/home

[54] https://it.wikipedia.org/wiki/File:Province_of_Bergamo_SRTM.png

[55] http://www.geoportale.regione.lombardia.it/

[56] http://www.geoportale.regione.lombardia.it/metadati?p_p_id=PublishedMetadata WAR_geoportalemetadataportlet $\& p \_p \_l i f e c y c l e=0 \& p \_p \_s t a t e=\operatorname{maximized} \& p \_p \_m$ ode=view\&_PublishedMetadata_WAR_geoportalemetadataportlet_view=editPublis hedMetadata\&_PublishedMetadata_WAR_geoportalemetadataportlet_uuid $=\{$ F391 D732-02CB-4EFE-BCD6-01C6068AD777\}\&_PublishedMetadata_WAR_geoportale metadataportlet_editType=view\&_PublishedMetadata_WAR_geoportalemetadatap ortlet_fromAsset=true\&rid=local

[57] http://www.vbtv.it/2015/10/09/part2-\%EF\%BB\%BF\%EF\%BB\%BFex-ferrovia-valle-b rembana-un-treno-carico-di-ricordi/

[58] https://www.dronezine.it

[59] Lemmens, M. (2018) Point Clouds. GIM International, 32, 5.

[60] https://www.enac.gov.it/Home/

[61] https://www.enac.gov.it/repository/ContentManagement/information/N122671512/ Reg_APR_Ed2_Em1.pdf

[62] Colombo, L. (2016) Nuvole di punti fra scansione laser e imaging di prossimità, qualche considerazione e riflessione. GEO Media, No. 2, 6-10.

[63] http://www.zf-laser.com

[64] https://www.nikon.it/it_IT/

[65] https://www.dji.com/

[66] https://eu.sokkia.com/it

[67] https://leica-geosystems.com/it-it

[68] http://www.agisoft.com/

[69] Schwind, M. and Starek, M. (2017) Structure from Motion Photogrammetry. GIM International, 36-39.

[70] Remondino, F. and El-Hakim, S. (2006) Image-Based 3D Modelling: A Review. The Photogrammetric Record, 115, 269-291.

https://doi.org/10.1111/j.1477-9730.2006.00383.x

[71] Guarnieri, A., Remondino, F. and Vettore, A. (2006) Digital Photogrammetry and TLS Data Fusion Applied to Cultural Heritage 3D Modeling. International Archives of Photogrammetry, Remote Sensing and Spatial Information Sciences, 36, 5. 
[72] Habib, A.F. (2017) UAV-Based Mobile Mapping: Potential, Challenges and Outlook. GIM International, 31, 31-33.

[73] Billjecki, F., Ledoux, H. and Stoter, J. (2014) Redefinig the Level of Detail for 3D Models. GIM International, 28, 21-23.

[74] https://www.autodesk.com/

[75] https://www.faro.com/

[76] http://www.meshlab.net/

[77] http://www.cloudcompare.org

[78] https://www.autodesk.it/products/autocad/overview

[79] http://3dmetrica.it/dtm-dsm-dem/

[80] https://www.gim-international.com/content/news/machine-learning-point-cloud-cl assification 